\title{
THE DOS 1 NEUTRON DOSIMETRY EXPERIMENT AT THE HB-4-A KEY 7 SURVEILLANCE SITE ON THE HFIR PRESSURE VESSEL
}

K. Farrell, F. B. Kam, C. A. Baldwin, J. V. Pace, III, W. R. Corwin, L. Robinson, F. F. Dyer, F. M. Haggag, F. W. Stallman, B. M. Oliver, and L. R. Greenwood

Date Published: January 1994

NOTICE: This document contains information of a preliminary nature. It is subject to revision or correction and therefore does not represent a final report.

Prepared for the U.S. Nuclear Regulatory Commission Office of Nuclear Regulatory Research and the U.S. Department of Energy Office of Basic Energy Sciences

Prepared by the OAK RIDGE NATIONAL LABORATORY

Oak Ridge, Tennessee 37831 managed by MARTIN MARIETTA ENERGY SYSTEMS, INC. for the

U.S. DEPARTMENT OF ENERGY under contract DE-AC05-84OR21400 


\section{CONTENTS}

$\underline{\text { Page }}$

LIST OF FIGURES $\ldots \ldots \ldots \ldots \ldots \ldots \ldots \ldots \ldots \ldots \ldots \ldots \ldots \ldots \ldots$

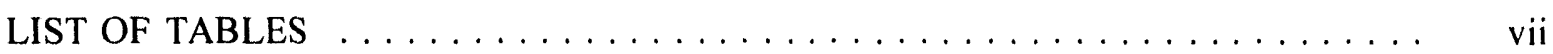

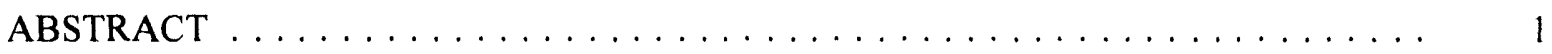

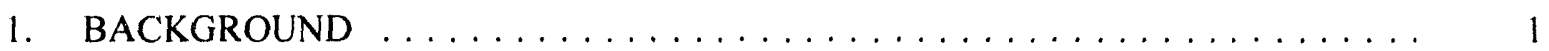

2. EXPERIMENTAL DETAILS $\ldots \ldots \ldots \ldots \ldots \ldots \ldots \ldots \ldots \ldots \ldots \ldots$

2.1 THE IRRADIATION LOCATION $\ldots \ldots \ldots \ldots \ldots \ldots \ldots \ldots \ldots$

2.2 THE CONTAINER .......................... 5

2.3 FLUX MONITOR MATERIALS AND

LOCATIONS IN PACKAGE .................... 8

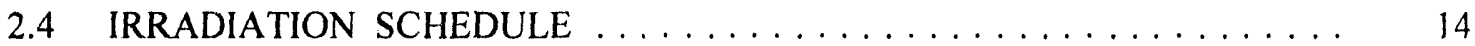

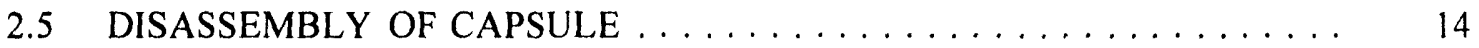

3. MEASUREMENTS AND RESULTS $\ldots \ldots \ldots \ldots \ldots \ldots \ldots \ldots \ldots \ldots \ldots$

3.1 RADIOACTIVATION MEASUREMENTS -

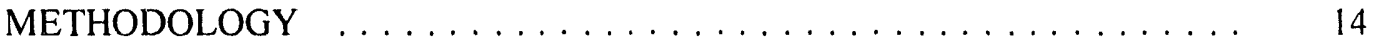

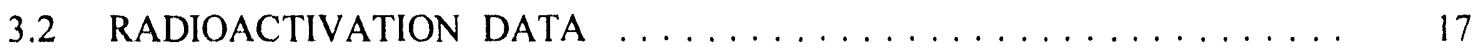

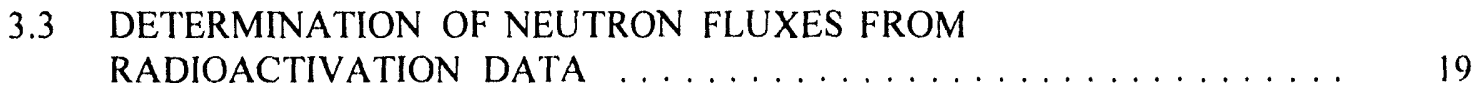

3.4 RESULTS FROM THE RADIOACTIVATION

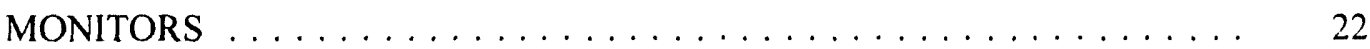

3.5 HELIUM MEASUREMENTS ON HAFMS -
METHODOLOGY $\ldots \ldots \ldots \ldots \ldots \ldots \ldots \ldots \ldots \ldots \ldots \ldots \ldots \ldots \ldots$

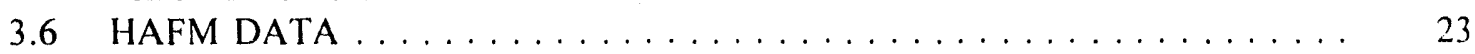

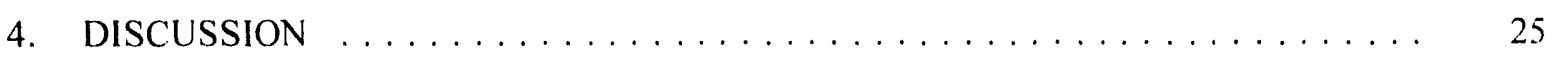

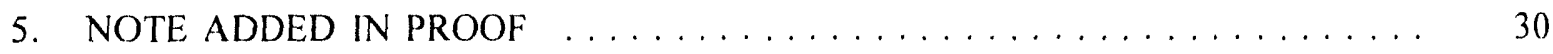

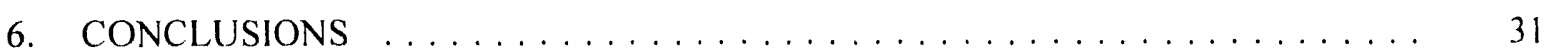

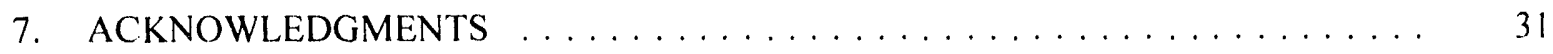

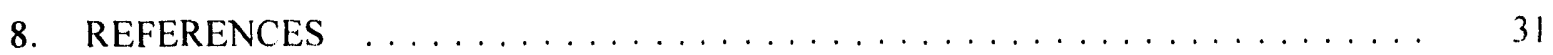

APPENDIX A. EARLY, COMPUTED NEUTRON SPECTRA FOR KEY 7, POSITIONS 6, 7, AND $8 \ldots \ldots \ldots \ldots \ldots \ldots \ldots$ 
Page

APPENDIX B. PROCEDURE FOR CALCULATING THE NEUTRON

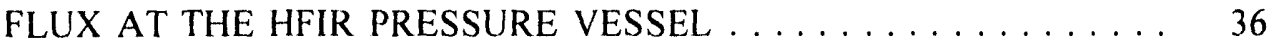

APPENDIX C. GROUP FLUXES FOR ALL POSITIONS IN

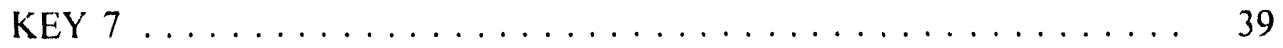

APPENDIX D. SOURCES AND CHEMICAL ANALYSES OF

MATERIALS USED IN DOS 1 DOSIMETRY

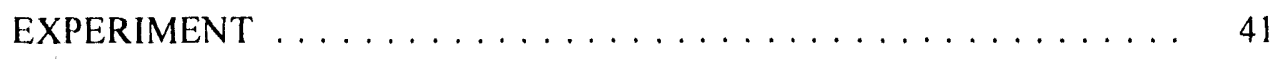

APPENDIX E. STANDARD SOLUTION OF RADIONUCLIDE

USED TO CALIBRATE GAMMA SPECTROSCOPES . . . . . . . 43

iv 


\section{LIST OF FIGURES}

\section{Figures}

1 Horizontal cross section through the High Flux Isotope Reactor at the core midplane, showing locations of the surveillance keys on the inner face of the vessel wall, and the position of the DOS 1 experiment in the key 7 rack

2 Sketch of a standard surveillance can, with usual complement of three Charpy impact bars and a stainless steel monitor wire lying in the Charpy vee notches

3 Details of a dosimeter block $\ldots \ldots \ldots \ldots \ldots \ldots \ldots \ldots \ldots \ldots$

4 Dosimetry package prior to closure, showing dosimeter vials in the

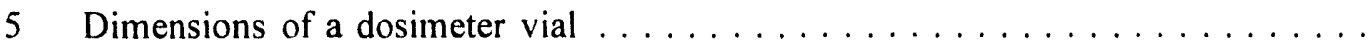

6 Schematic representation of the power-time history of High Flux Isotope Reactor cycle No. 305 


\section{LIST OF TABLES}

Tables

$\underline{\text { Page }}$

1 Identification of monitor materials and their wrapper materials $\ldots \ldots \ldots \ldots \ldots$

2 Position assignments for the monitor vials $\ldots \ldots \ldots \ldots \ldots \ldots \ldots \ldots \ldots$

3 Gamma-counting conditions for the DOS 1 flux monitors $\ldots \ldots \ldots \ldots \ldots$

4 Activities of flux monitors $\ldots \ldots \ldots \ldots \ldots \ldots \ldots \ldots \ldots \ldots \ldots$

5 Neutron fluxes obtained from the radioactiviation monitors $\ldots \ldots \ldots \ldots \ldots$

6 Helium concentrations measured for the helium accumulation

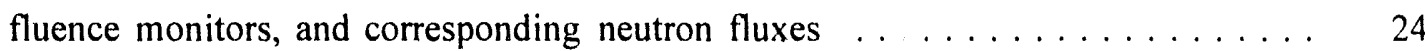

7 Summary of neutron flux measurements and recent calculated

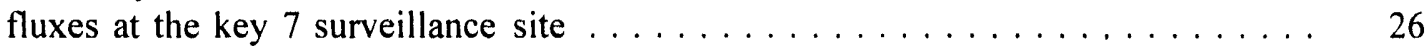

8 Determination of mass of ${ }^{237} \mathrm{~Np}$ in $\mathrm{Np}$ monitors, using ${ }^{233} \mathrm{~Pa}$ activities . . . . . . 29 


\title{
THE DOS 1 NEUTRON DOSIMETRY EXPERIMENT AT THE HB-4-A KEY 7 SURVEILLANCE SITE ON THE HFIR PRESSURE VESSEL ${ }^{*}$
}

\author{
K. Farrell, F. B. Kam, C. A. Baldwin, J. V. Pace, III, \\ W. R. Corwin, L. Robinson, F. F. Dyer, F. M. Haggag. \\ F. W. Stallman. B. M. Oliver ${ }^{\dagger}$, and L. R. Greenwood ${ }^{\dagger}$
}

\begin{abstract}
A comprehensive neutron dosimetry experiment was made at one of the prime surveillance sites at the High Flux Isotope Reactor (HFIR) pressure vessel to aid radiation embrittlement studies of the vessel and to benchmark neutron transport calculations. The thermal neutron flux at the key 7, position 5 site was found, from measurements of radioactivation of four cobalt wires and four silver wires, to be $2.4 \times 10^{12} \mathrm{n} \cdot \mathrm{m}^{-2} \cdot \mathrm{s}^{-1}$. The thermal flux derived from two helium accumulation monitors was $2.3 \times 10^{12} \mathrm{n} \cdot \mathrm{m}^{-2} \cdot \mathrm{s}^{-1}$. The thermal flux estimated by neutron transport calculations was $3.7 \times 10^{12} \mathrm{n} \cdot \mathrm{m}^{-2} \cdot \mathrm{s}^{-1}$. The fast flux, $>1 \mathrm{MeV}$, determined from two nickel activation wires, was $1.5 \times 10^{12} \mathrm{n} \cdot \mathrm{m}^{-2} \cdot \mathrm{s}^{-1}$, in keeping with values obtained earlier from stainless steel surveillance monitors and with a computed value of $1.2 \times 10^{12} \mathrm{n} \cdot \mathrm{m}^{-2} \cdot \mathrm{s}^{-1}$. The fast fluxes given by two reactionproduct-type monitors. neptunium-237 and beryllium, were $2.6 \times 10^{13} \mathrm{n} \cdot \mathrm{m}^{-2} \cdot \mathrm{s}^{-1}$ and $2.2 \times 10^{13} \mathrm{n} \cdot \mathrm{m}^{-2} \cdot \mathrm{s}^{-1}$. respectively. Follow-up experiments indicate that these latter high values of fast flux are reproducible but are false: they are due to the creation of greater levels of reaction products by photonuclear events induced by an exceptionally high ratio of gamma flux to fast neutron flux at the vessel.
\end{abstract}

\section{BACKGROUND}

When the High Flux Isotope Reactor (HFIR) was commissioned in 1965, a surveillance program was initiated to periodically measure any service-induced changes in the mechanical properties of the reactor's ferritic steel pressure vessel. Racks of surveillance packages, each containing three Charpy impact test specimens of the vessel materials. are located at sensitive positions around the inside surface of the vessel at the horizontal centerline of the core. These

\footnotetext{
${ }^{*}$ Research supported in part by the Office of Nuclear Regulatory Research, U.S. Nuclear Regulatory Commission, under Interagency Agreement DOE 1886-8109-8L with the U.S. Department of Energy and in part by the Division of Materials Sciences, U.S. Department of Energy, under contract DE-AC05-84OR21400 with Martin Marietta Energy Systems, Inc.

${ }^{\dagger}$ Rockwell International Corporation, Canoga Park. California.

‡Battelle Northwest Laboratories, Richland, Washington.
} 
packages are removed at prescribed intervals, and the Charpy bars are tested to check for any deterioration in crack resistance. A single stainless steel flux monitor wire is carried in the aligned vee notches of the Charpy bars, and the gamma ray emissions from decay of $\mathrm{Co}^{58}$ and $\mathrm{Mn}^{54}$ produced by activation of $\mathrm{Ni}$ and $\mathrm{Fe}$ in the wire are measured to sbtain the fast flux, $>1 \mathrm{MeV}$. The neutron spectrum is derived by neutron transport calculations. No comprehensive dosimetry has been done to experimentally confirm the calculated neutron spectrum at the vessel.

In 1986, the surveillance program revealed that the Charpy specimens were becoming embrittled at a faster rate than was expected from the test reactor data used to design the reactor. ${ }^{\prime}$ A search for the cause(s) of the accelerated embrittlement is centered on potential effects of very low neutron flux and softened neutron spectrum. ${ }^{2-4}$ These features, and the low temperature $\left(\sim 50^{\circ} \mathrm{C}\right)$, are also common to the vessel support structures of commercial power reactors. Therefore. the Nuclear Regulatory Commission (NRC) and the Division of Materials Sciences of the Office of Basic Energy Sciences of the Department of Energy are cooperating to investigate the embrittlement via the NRC Heavy-Section Steel Irradiation (HSSI) Program at Oak Ridge National Laboratory (ORNL). One goal of the investigation is to determine the neutron fluxes and spectra at the vessel surveillance locations.

The surveillance sites at the HFIR pressure vessel are known as "keys." There are seven of these keys located as shown in Fig. 1, which is a horizontal cross section through the reactor at the core midplane. Four of the keys, Nos. 1, 2, 3, and 4, are carousels that encircle the four beam tubes, HB-1, etc. Keys 5, 6, and 7 are horizontal racks on the beltline. Each rack or carousel is slotted to hold five to ten flat, stainless steel cans containing the Charpy bars. The racks and carousels stand off from the vessel at a distance of only 10 to $20 \mathrm{~mm}$, the gap being filled with water. Thus, the exposure lead factor at the cans is minimal, and the surveillance specimens receive neutron exposures that should be representative of those at the inner surface of the pressure vessel. Much of the surveillance data was obtained from Charpy specimens removed from the key 7 position. Accordingly, determinations of flux and spectrum have focussed initially on the key 7 position.

Results from early neutron transport calculations ${ }^{5}$ of the spectrum at three positions in the key 7 rack are listed in Appendix A. These indicate that the fast $(>1 \mathrm{MeV})$ flux is in the range 1.5 to $2 \times 10^{12} \mathrm{n} \cdot \mathrm{m}^{-2} \cdot \mathrm{s}^{-1}$ and the spectrum is considerably softened, with thermal $(\mathrm{E}<0.414 \mathrm{eV}$ )-to-fast flux ratios in the range 28 to 75 . These data provided the basis for a 
ORNL-DWG 92M-15808R

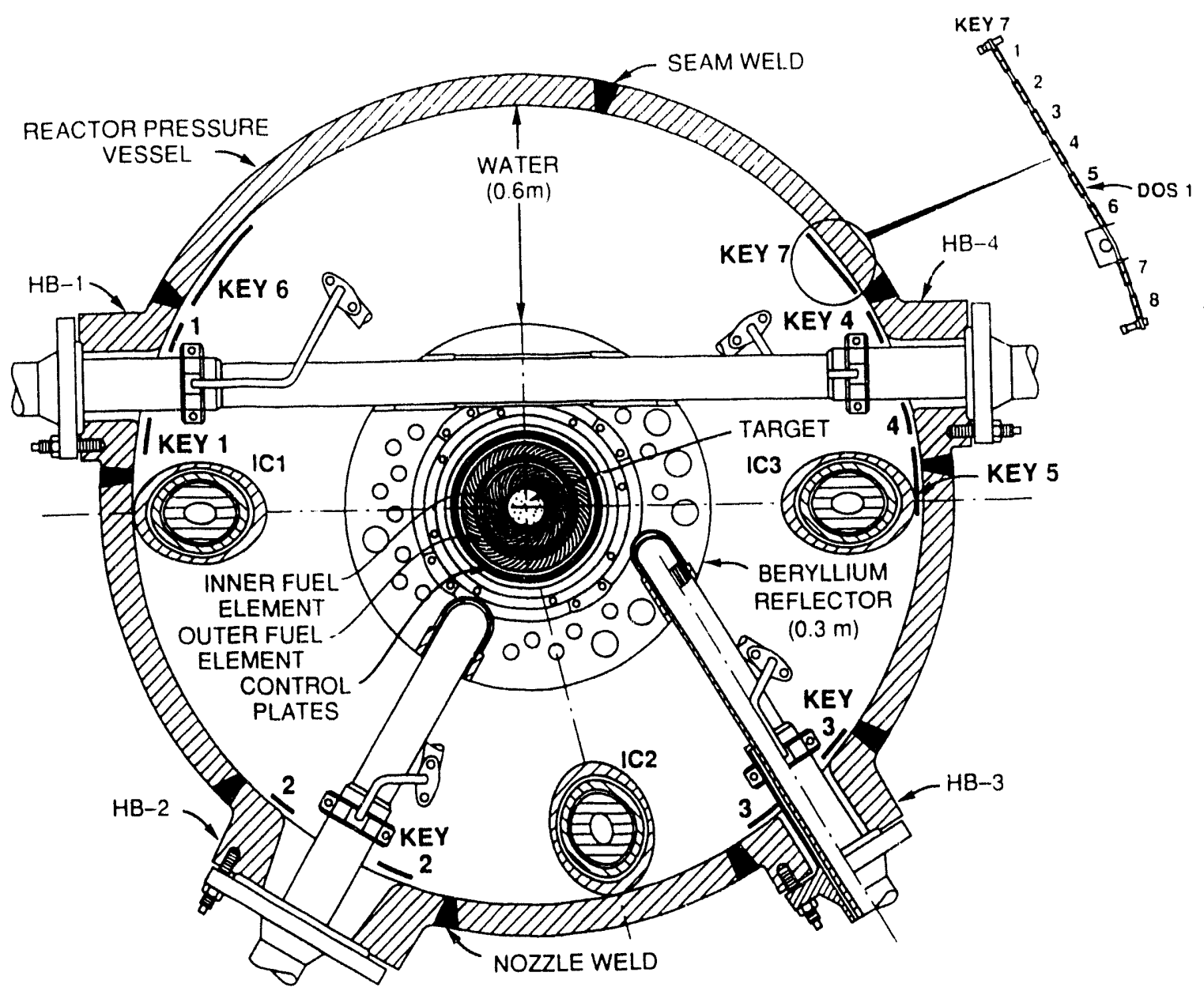

Fig. 1. Horizontal cross section through the High Flux Isotope Reactor at the core midplane, showing locations of the surveillance keys on the inner face of the vessel wall, and the position of the DOS 1 experiment in the key 7 rack. 
model showing that a soft spectrum could cause the accelerated embrittlement of the surveillance specimens. ${ }^{2,3}$ It was later recognized that when the original spectrum calculations were made, the primary goal had been to determine the fast flux, and although a thermal flux was also developed, it was considered to be in error because the transport cross sections had been produced to examine non-thermal systems. Consequently, late in 1991, the flux computations were repeated using more relevant, updated transport cross sections and more sophisticated transport codes. The procedures ${ }^{6}$ used are given in Appendix B. The computations were extended ${ }^{7}$ to cover other surveillance keys, too. The results for all eight positions in the key 7 site are given in Appendix C. These new calculations for key 7 give thermal fluxes an order of magnitude lower than the older ones.

These disparate flux estimates created an unsatisfactory situation. Although the newer calculations were believed to be more reliable, it was acknowledged that an experimental measure of thermal flux was required to settle the issue and to provide a concrete benchmark for calibration of future computations. The issue was considered important enough to justify a prompt dosimetry experiment. The HFIR vessel surveillance sites are accessible only during fuel changes, and because there was only one more fuel cycle scheduled before a planned, prolonged maintenance shutdown of the HFIR occurred, an immediate dosimetry experiment, named the DOS 1 experiment, was instituted. A preliminary report ${ }^{8}$ of this experiment was delivered to the NRC in April 1992 pending further investigation of some ambiguous results. The measurements of thermal flux were conclusive and were in fair agreement with the new, calculated thermal flux. Unexpected and unusual results were obtained for the fast flux. The exceptional nature of these fast flux data has drawn searching scrutiny. This has not only diverted attention from the successful procurement of the thermal flux data but has created a demand for a detailed description of the experiment that goes beyond the norm. This final report of the DOS 1 experiment is construed to satisfy that demand.

\section{EXPERIMENTAL DETAILS}

\subsection{THE IRRADIATION LOCATION}

The surveillance site chosen for the DOS 1 experiment was the HB-4-A, key 7 location, which is on the beltline adjacent to, and on the high fluence side of, beam tube HB-4. The key 7 site is regarded as being symmetrical with key 6 , and the neutron fluxes should be similar. 
The other keys see dissimilar fluxes because of various degrees of neutron streaming or shielding by beam tubes and other equipment. The key 7 rack has slots for eight surveillance capsules, as shown in the insert in Fig. 1. The number 5 position was occupied by a spare surveillance package whose ternporary removal to accommodate the DOS 1 package would not compromise the surveillance program. Accordingly, key 7, position 5 was used for the DOS 1 dosimeter package.

\subsection{THE CONTAINER}

This experiment was intended to reproduce the physical conditions in a surveillance package. Therefore, the vehicle selected to carry the flux monitors was a standard surveillance can provided from the inventory of the surveillance program. These cans are manufactured from 304L stainless steel to HFIR standards in accordance with HFIR drawing No. E49945, Rev. C, dated 9-25-87. An excerpt from this drawing, giving the major dimensions of the can, is displayed in Fig. 2. The inside of the can is sized to hold three Charpy impact specimens, side by side. The particular can used in this experiment had the identity number $87-13$ engraved on its bottom edge, opposite the bail. Further details of this container are available in its quality assurance documents recorded in File JOB 5-1-143 in the Research Reactors Division (RRD) Document Control Center. To distinguish the can easily from surveillance packages in the key 7 rack under water, the upper surface of its bail was engraved with the characters DOS 1, and a notch was cut into the bail.

To simulate the mass of three ferritic steel Charpy bars, a pair of carbon steel dosimeter holder blocks were machined to the dimensions shown in Fracture Mechanics Group drawing No. DOSHDH01 r. 0, dated 10-1-92 (see Fig. 3). Five matching, closed slots were cut into the mating surfaces of the two blocks. One block was laid in the stainless steel can, face up, and with slot I toward the bail. A preassigned vial of dosimeter materials was laid in each slot, and a photograph (see Fig. 4) was taken to verify and record the positioning of the vials. The matching block was then placed face down over the first block to sandwich the vials in the slots. The stainless steel cover plate was placed over the blocks, and the assembly was clamped between two large, aluminum plate heat sinks with just $3 \mathrm{~mm}$ of one edge protruding. This edge was sealed by tungsten arc welding under an argon cover gas, following procedure WPS-307ASME2, as specified in drawing No. E49945, Rev. C. Three of the four edges were welded in this manner, leaving the bottom edge (opposite the bail end) unsealed. The package was transferred to a glove box where it was pumped under vacuum overnight. Helium gas was then 
ORNL-DWG E49945 Rev. C

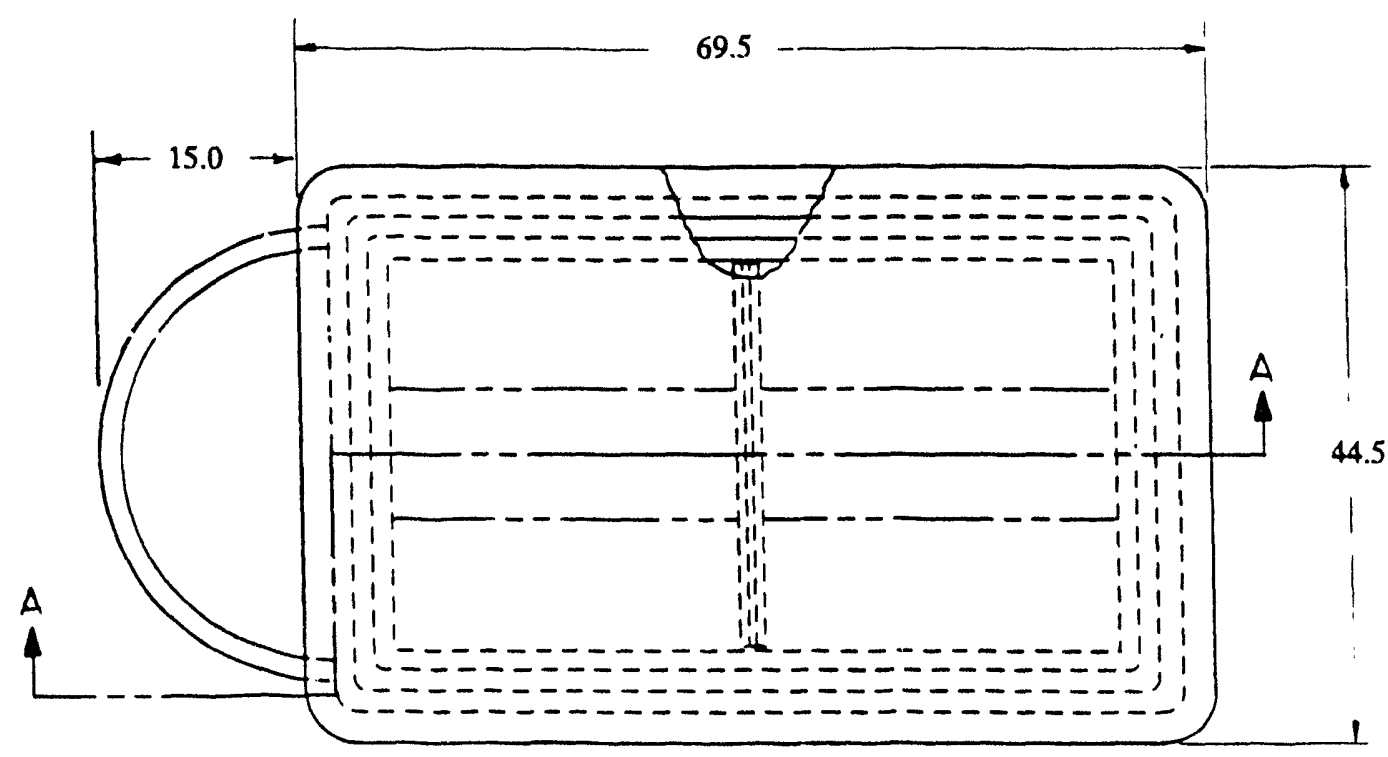

SURVEILLANANE SPECIMEN ASSY

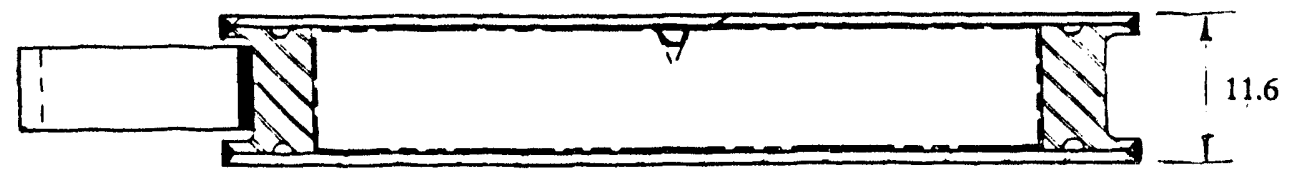

\section{SECTION A-A}

Dimensions are in $\mathrm{mm}$.

Fig. 2. Sketch of a standard surveillance can, with usual complement of three Charpy impact bars and a stainless steel monitor wire lying in the Charpy vee notches. 


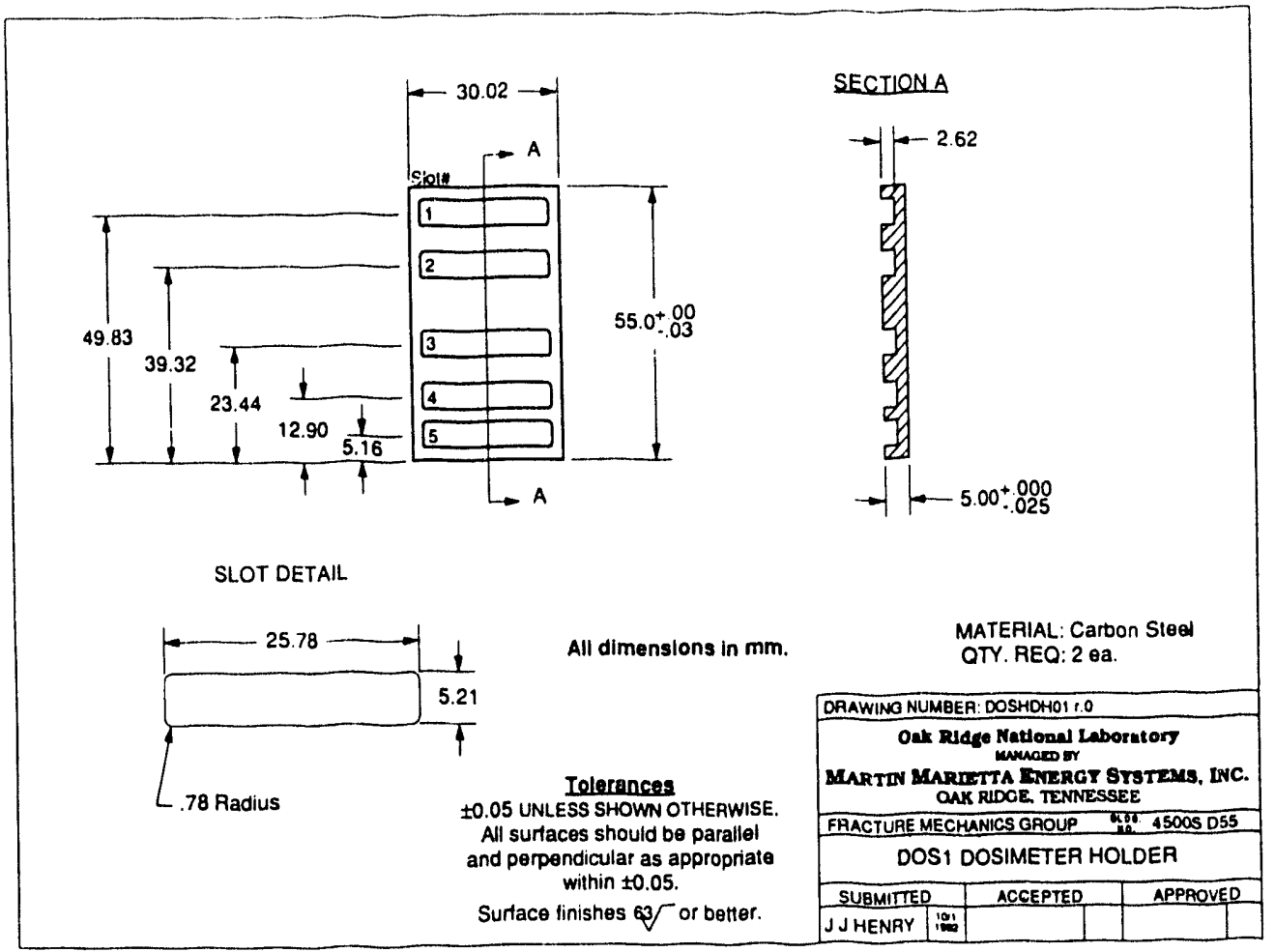

Fig. 3. Details of a dosimeter block.
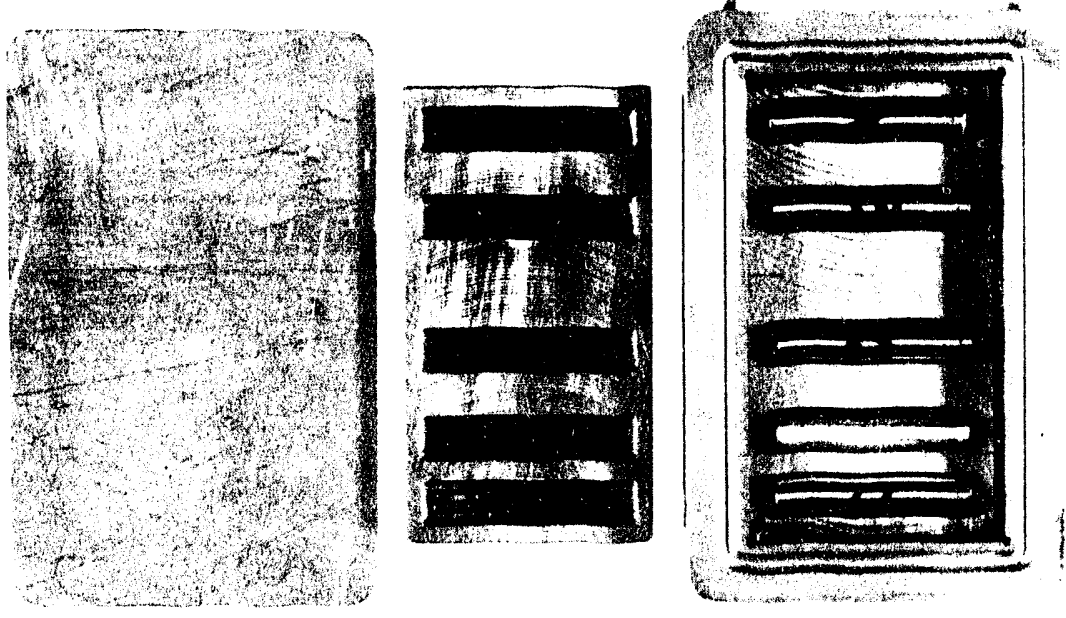

$\overbrace{}^{\min 10}$

Fig. 4. Dosimetry package prior to closure, showing dosimeter vials in the slotted block. 
admitted to the glove box, and the open edge of the can was sealed by heliarc welding. This closure welding in helium was performed to ensure that the can was filled with helium to facilitate subsequent helium leak detection, a requirement of the procedure for the assembly of surveillance packages.

Following welding, the assembly was helium leak tested as specified on the capsule drawing. The package was then subjected to a hydrostatic pressure of $67.9 \mathrm{MPa}$ for $5 \mathrm{~min}$ to collapse the cover plates onto the dosimeter holder blocks in order to maximize heat transfer during irradiation. The outline of the blocks was clearly visible in the cover plates after pressurization. Helium leak testing was repeated with no signs of leaks, and the package was cleaned in acetone and alcohol in accordance with HFIR Procedure RRD-JS-31, Rev. 0. The weld inspection reports and leak testing reports were submitted to the Reactor Experiments Officer with the DOS 1 irradiation request documents.

\subsection{FLUX MONITOR MATERIALS AND LOCATIONS IN PACKAGE}

The purpose of this experiment was to measure the flux of thermal neutrons. Accordingly, the majority of the monitors were thermal neutron response types. The selection of monitor materials was limited by two factors: a low activation level because of the low fluxes and short exposure period, and an expected delay period of several days between cessation of exposure and retrieval of the specimens. The delay was due to a combination of cooldown requirements for the reactor and the time needed to recover the container and dismantle it. So, weakly activating and materials with short-lived activity were eliminated. The choice fell on wires of $\mathrm{Ag}, \mathrm{Au}$, and $\mathrm{Co}$, which were available onsite in our dosimetry inventory. Even with these materials, it was necessary to use them in their pure, concentrated state rather than in their more conventional, diluted (alloyed) condition in order to achieve measurable levels of activation. The wire sizes were 0.25 to $0.50 \mathrm{~mm}$ diam by 10 to $30 \mathrm{~mm}$ long, weighing 9 to $60 \mathrm{mg}$. Their sources and chemical analyses are given in Appendix D.

The fast flux was addressed primarily with wires of pure Ni to simulate the Ni activation measured on the standard stainless steel monitor wire used in surveillance capsules. To provide backup measurements of fast flux from a different material, a conventional fission-type monitor of $\mathrm{Np}^{237}$ was included. The $\mathrm{Np}$ was in the form of a compacted wire of $\mathrm{NpO}_{2}$ sealed in a small, welded vanadium capsule. This was an off-the-shelf monitor from a production batch that has supplied such monitors for many dosimeter experiments. Incorporation of a fission monitor in the experiment required the use of a shielding material to reduce the number of thermal neutrons 
reaching the monitor. For that reason, the $\mathrm{Np}$ capsule was enclosed in a gadolinium vial. The gadolinium vial was also used to hold some of the thermal neutron activation wires to determine the activity contribution from neutrons with energies above the gadolinium cutoff energy.

This experiment provided an opportunity to use and test some different, non-activationtype dosimeters that have proved to be very satisfactory in dosimetry experiments elsewhere. These are helium accumulation fluence monitors (HAFMs). They are described in American Society for Testing and Materials (ASTM) Standard E910-89 (ref. 9). HAFMs produce a stable reaction product, helium, that can be measured accurately. An advantage of HAFMs is that since the reaction product does not undergo radioactive decay, they can be measured at leisure, and pieces can be stored indefinitely for future remeasurement, if desired. The HAFMs chosen for this experiment consisted of wires $(0.5 \mathrm{~mm}$ diam by 12 to $14 \mathrm{~mm}$ long; 7 to $8 \mathrm{mg}$ mass $)$ of $\mathrm{Al}-0.7 \mathrm{wt} \% \mathrm{Li}$ and $\mathrm{Al}-0.5 \mathrm{wt} \% \mathrm{~B}$ for thermal neutron measurements and chips ( $8 \mathrm{mg})$ of $\mathrm{Be}$ for fast neutrons. These HAFMs were provided by Rockwell International Corporation from their characterized stock; their chemical analyses are given in Appendix $\mathrm{D}$.

These monitor materials were packaged in five vials, one for each of the slots in the dosimeter block. Each vial did not contain the same monitors. Details of the vials and their contents are given in Table 1. The identities of the wires in each vial were discriminated by their diameters, lengths, and masses. Four of the vials were made from 6061-T6 aluminum alloy. The fifth vial was the aforementioned gadolinium shield for the $\mathrm{Np}$ monitor. All five vials were of equal dimensions and were hollow cylinders machined from solid rod stock, with one blind end, and the other end closed with a push-fitted plug. Figure 5 is a sketch of the gadolinium vial; the wall thickness was .035 in. $(0.9 \mathrm{~mm})$. One of the aluminum vials was assigned to carry all the HAFMs and no other monitors. This vial, on which was retained its original as-manufactured identity number of $\mathrm{H} 51$, was sealed by electron beam ivelding in vacuum to protect the HAFMs from contamination by the helium atmosphere in the outer container of the experiment. After welding, the $\mathrm{H} 51$ vial was leak tested to ensure its integrity. The other four vials were closed by plugging them, then wrapping them tightly with aluminum foil to secure the plugs. All vials were engraved with their I.D. marks. Additionally, the four foil-wrapped vials were clearly marked with a permanent felt-tip pen. The positions of the vials in the dosimeter block are given in Table 1 and are repeated in a simpler format in Table 2. Vial $\mathrm{C}$ in slot 3 is a duplicate of vial B to test whether the proximity of the gadolinium vial in 
Table 1. Identification of monitor materials and their wrapper materials

Experiment/Location: HFIR DOSIMETRY EXPERIMENT, CYCLE 305, HB-4-A (KEY 7), POSITION 5, COMPACT SLOT MUMBER 1

Experiment/Location: HFIR DOSIMETRY EXPERIMENT Cimensions: $4.83 \mathrm{~mm} 00 \times 3.05 \mathrm{~mm}$ ID $23.4 \mathrm{~mm}$ - Mass: $2.29 \mathrm{~g}$ Loaded by: CAB

\begin{tabular}{|c|c|c|c|c|c|c|c|c|c|c|c|}
\hline \multirow{2}{*}{ Material } & \multirow{2}{*}{ Supplier } & \multirow{2}{*}{$\begin{array}{l}\text { Batch } \\
\text { number }\end{array}$} & \multirow{2}{*}{ Description } & \multirow{2}{*}{$\begin{array}{c}\begin{array}{c}\text { Material } \\
\text { mass } \\
\text { (mg) }\end{array} \\
\end{array}$} & \multicolumn{6}{|c|}{ Encapsulated monitor description } & \multirow{2}{*}{ Comments } \\
\hline & & & & & Mat. & $\infty$ & 10 & Length & Mass & Ident & \\
\hline Au & $\begin{array}{l}\text { Johnson } \\
\text { Mat they }\end{array}$ & $\begin{array}{c}1521 \\
\text { Lot } \$ 10967 \mathrm{~A} \\
\end{array}$ & $0.25 \mathrm{~mm}$ dia $\times 10 \mathrm{~mm}$ wire & 9.028 & MA & & & & & & \\
\hline Ag & $\begin{array}{l}\text { Johnson } \\
\text { Mat they }\end{array}$ & $\begin{array}{c}4110 i s \\
\text { Lot } \$ 11468\end{array}$ & $0.25 \mathrm{~mm}$ dia $\times 30 \mathrm{~mm}$ wire & 15.641 & MA & & & & & & $\begin{array}{l}\text { wire is folded } \\
\text { in half }\end{array}$ \\
\hline Co & ORNL & Lot \#1 & $0.50 \mathrm{~mm}$ dia $\times 10 \mathrm{~mm}$ wire & 17.983 & MA & & & & & & \\
\hline $\mathrm{Ni}$ & MRC & \begin{tabular}{|c|}
$28 / 006344-$ \\
020481
\end{tabular} & $0.50 \mathrm{~mm}$ dia $\times 30 \mathrm{~mm}$ wire & 60.523 & MA & & & & & & $\begin{array}{l}\text { wire is folded } \\
\text { in half }\end{array}$ \\
\hline \multirow[t]{2}{*}{$237 \mathrm{NpO}_{2}$} & ORNL & $83-1$ & $0.46 \mathrm{~mm}$ dia oxide wire & $\mathrm{NpO}_{2} \quad 9.368$ & $\mathbf{v}$ & $\begin{array}{c}1.27 \\
\mathrm{~mm}\end{array}$ & $\begin{array}{c}0.79 \\
\mathrm{~mm}\end{array}$ & $\begin{array}{l}8.64 \\
\mathrm{~mm}\end{array}$ & $\begin{array}{c}54.2 \\
\mathrm{mg} \\
\end{array}$ & $\# 10$ & $\begin{array}{l}\text { welded vanadium } \\
\text { container }\end{array}$ \\
\hline & & & & ${ }^{237}{ }_{\mathrm{MP}} 8.253$ & & & & & & & elemental mass \\
\hline
\end{tabular}

Cont... 
Table 1 (Cont.)

EXperiment/Location: HFIR DOSIMETRY EXPERIMENT, CYCLE $305 /$ HB-4-A (KEY 7), POSITION 5, COMPACT SLOT MUMBER 2

Container - ID: $\quad$ B - Material: $A$ Al-6061-T6 - Dimensions: $4.83 \mathrm{~mm} 00 \times 3.05 \mathrm{~mm} 10 \times 23.4 \mathrm{~mm}$ - Mass: $0.78 \mathrm{~g}$ Loaded by: CAB

\begin{tabular}{|c|c|c|c|c|c|c|c|c|c|c|c|}
\hline \multirow{2}{*}{ Material } & \multirow{2}{*}{ Supplier } & \multirow{2}{*}{$\begin{array}{l}\text { Batch } \\
\text { number }\end{array}$} & \multirow{2}{*}{ Description } & \multirow{2}{*}{$\begin{array}{l}\text { Material } \\
\text { mass } \\
\text { (mg) }\end{array}$} & \multicolumn{6}{|c|}{ Encapsulated monitor description } & \multirow{2}{*}{ Cormments } \\
\hline & & & & & Mat. & $\infty$ & ID & Length & Mass & Ident & \\
\hline Au & $\begin{array}{l}\text { Johnson } \\
\text { Mat they }\end{array}$ & $\begin{array}{c}1521 \\
\operatorname{Lot} \# 10967 \mathrm{~A}\end{array}$ & $0.25 \mathrm{~mm}$ dia $\times 10 \mathrm{~mm}$ wire & 8.263 & HA & & & & & & \\
\hline Ag & $\begin{array}{l}\text { Johnson } \\
\text { Mat they }\end{array}$ & $\begin{array}{c}\text { W11073 } \\
\text { Lot } \# 11468\end{array}$ & $0.25 \mathrm{~mm}$ dia $\times 30 \mathrm{~mm}$ wire & 15.753 & NA & & & & & & $\begin{array}{l}\text { wire is folded } \\
\text { in half }\end{array}$ \\
\hline Co & ORNL & Lot $\# 1$ & $0.50 \mathrm{~mm}$ dia $\times 10 \mathrm{~mm}$ wire & 18.723 & MA & & & & & & \\
\hline
\end{tabular}

EXperiment/Location: HFIR DOSIMETRY EXPERIMENT, CYCLE 305 L HB-4-A (XEY 7), POSITION 5, COMPACT SLOT NUMBER 3

Container - 10: c - Material: Al-6061-16 - Dimensions: $4.83 \mathrm{~mm} 00 \times 3.05 \mathrm{~mm} 10 \times 23.4 \mathrm{~mm}$ - Mass: $0.78 \mathrm{~g}$ Loaded by: CAB

\begin{tabular}{|c|c|c|c|c|c|c|c|c|c|c|c|}
\hline \multirow{2}{*}{ Material } & \multirow{2}{*}{ Supplier } & \multirow{2}{*}{$\begin{array}{l}\text { Batch } \\
\text { number }\end{array}$} & \multirow{2}{*}{ Description } & \multirow{2}{*}{$\begin{array}{l}\text { Material } \\
\text { mass } \\
(m g)\end{array}$} & \multicolumn{6}{|c|}{ Encapsulated monitor description } & \multirow{2}{*}{ Comments } \\
\hline & & & & & Mat. & $\infty$ & 10 & Length & Mass & Ident & \\
\hline Au & $\begin{array}{l}\text { Johnson } \\
\text { Mat they }\end{array}$ & $\begin{array}{c}1521 \\
\text { Lot\#10967A }\end{array}$ & $0.25 \mathrm{~mm}$ dia $\times 10 \mathrm{~mm}$ wire & 8.494 & NA & & & & & & . \\
\hline Ag & $\begin{array}{l}\text { Johnson } \\
\text { Mat they }\end{array}$ & $\begin{array}{c}W 11073 \\
\text { Lot } \# 11468\end{array}$ & $0.25 \mathrm{~mm}$ dia $\times 30 \mathrm{~mm}$ wire & 15.362 & MA & & & & & & $\begin{array}{l}\text { wire is folded } \\
\text { in half }\end{array}$ \\
\hline Co & ORNL & Lot \#1 & $0.50 \mathrm{~mm}$ dia $\times 10 \mathrm{~mm}$ wire & 18.623 & Ma & & & & & & \\
\hline
\end{tabular}

Cont... 
Table 1 (Cont)

EXperiment/Location: HFIR DOSIMETRY EXPERIMENT, CYCLE $305 /$ HB-4-A (KEY 7), POSIIIION 5, COMPACT SLOT MUMBER 4 (TO BE RETURMED TO ROCKLELL) Container - 10: H51 - Material: Al-6061-T6 - Dimensions: $4.83 \mathrm{~mm} \mathrm{00} \times 3.05 \mathrm{~mm} 10 \times 23.4 \mathrm{~mm}$ - Mass: $0.78 \mathrm{~g}$ Loaded by: CAB

\begin{tabular}{|c|c|c|c|c|c|c|c|c|c|c|c|}
\hline \multirow[b]{2}{*}{ Material } & \multirow[b]{2}{*}{ Supplier } & \multirow{2}{*}{$\begin{array}{l}\text { Batch } \\
\text { number }\end{array}$} & \multirow{2}{*}{ Description } & \multirow{2}{*}{$\begin{array}{c}\text { Material } \\
\text { mass } \\
\text { (mg) }\end{array}$} & \multicolumn{6}{|c|}{ Encapsulated monitor description } & \multirow{2}{*}{ Comments } \\
\hline & & & & & Mat. & $\infty$ & 10 & Length & Mass & Ident & \\
\hline $0.7 \mathrm{wtX} \mathrm{Li/Al}$ & Rockwell & Lot $* 5$ & $0.50 \mathrm{~mm}$ dia $\times 12 \mathrm{~mm}$ uire & 6.965 & MA & & & & & & \\
\hline $0.5 \mathrm{wtX} \mathrm{B} / \mathrm{Al}$ & Rockwell & Lot \#6 & $0.50 \mathrm{~mm}$ dia $\times 14 \mathrm{~mm}$ wire & 8.188 & NA & & & & & & \\
\hline $99.99 \% \mathrm{Be}$ & Rockwell & Lot 7 & $2 \mathrm{~mm} \times 2^{\text {HFIR-Be-2 } \mathrm{mm} \times 7 \mathrm{~mm} \text { chips }}$ & $\begin{array}{l}8.840 \\
\text { total }\end{array}$ & NA & & & & & & $\begin{array}{l}3 \text { chips urapped } \\
\text { in aluminum foil }\end{array}$ \\
\hline
\end{tabular}

EXperiment/Location: HFIR DOSIMETRY EXPERIMENT, CYCLE 305/ HB-4-A (KEY 7), POSITION 5, COMPACT SLOT MUMBER 5

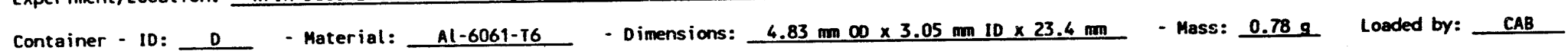

\begin{tabular}{|c|c|c|c|c|c|c|c|c|c|c|c|}
\hline \multirow[b]{2}{*}{ Material } & \multirow[b]{2}{*}{ Suppl ier } & \multirow{2}{*}{$\begin{array}{l}\text { Batch } \\
\text { number }\end{array}$} & \multirow{2}{*}{ Description } & \multirow{2}{*}{$\begin{array}{c}\text { Material } \\
\text { mass } \\
\text { (mg) }\end{array}$} & \multicolumn{6}{|c|}{ Encapsulated monitor description } & \multirow{2}{*}{ Comments } \\
\hline & & & & & Mat. & $\infty$ & 10 & Length & Mass & Ident & \\
\hline in & $\begin{array}{l}\text { Jchnson } \\
\text { Mat they }\end{array}$ & $\begin{array}{c}1521 \\
\text { Lot\#10967A }\end{array}$ & $0.25 \mathrm{~mm}$ dia $\times 10 \mathrm{~mm}$ wire & 8.185 & MA & & & & & & \\
\hline Ag & $\begin{array}{l}\text { Johnson } \\
\text { Mat they }\end{array}$ & $\begin{array}{c}411073 \\
\text { Lot } \$ 11468 \\
\end{array}$ & $0.25 \mathrm{~mm}$ dia $\times 30 \mathrm{~mm}$ wire & 15.669 & Ma & & & & & & $\begin{array}{l}\text { wire is folded } \\
\text { in half }\end{array}$ \\
\hline co & ORNL & $\operatorname{Lot} * 1$ & $0.50 \mathrm{~mm}$ dia $\times 10 \mathrm{~mm}$ wire & 18.023 & MA & & & & & & \\
\hline $\mathrm{Ni}$ & MRC & \begin{tabular}{|l|}
$28 / 006344-$ \\
020481
\end{tabular} & $0.50 \mathrm{~mm}$ dia $\times 30 \mathrm{~mm}$ wire & 58.423 & MA & & & & & & $\begin{array}{l}\text { wire is folded } \\
\text { in half }\end{array}$ \\
\hline
\end{tabular}


ORNL-DWG 93M-11347

VIAL BODY
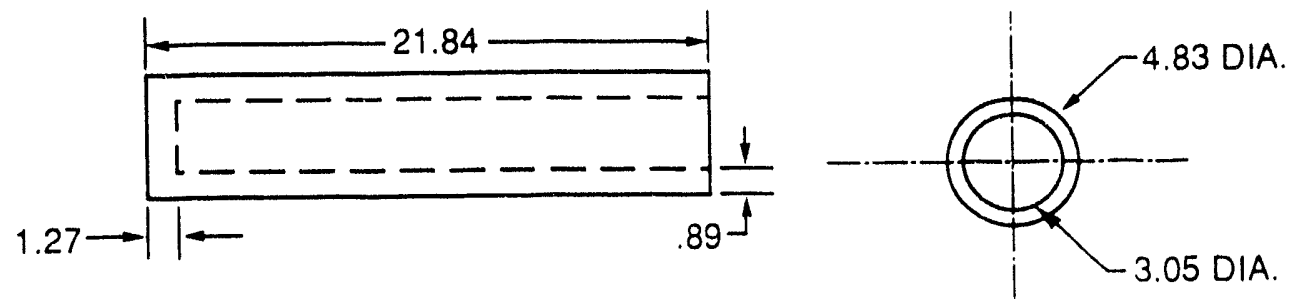

VIAL CAP
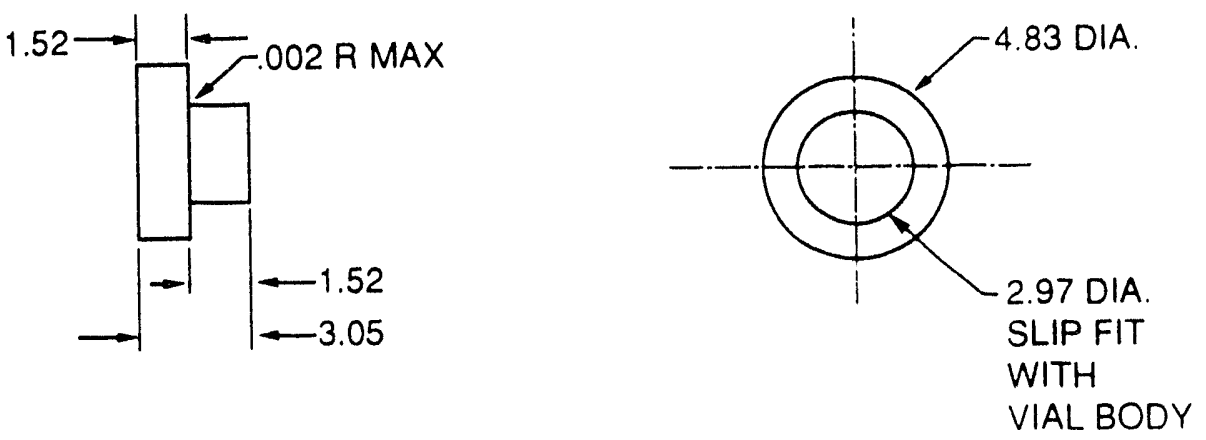

ALL DIMENSIONS IN mm.TOLERANCES: \pm 0.05 UNLESS NOTED OTHERWISE. NOT TO SCALE

Fig. 5. Dimensions of a dosimeter vial.

Table 2. Position assignments for the monitor vials

\begin{tabular}{cccc}
\hline \hline Slot No. & Vial ID & Vial Cover & Monitor Materials \\
\hline 1 & $\mathrm{~A}$ & Gadolinium & $\mathrm{Ag}, \mathrm{Au}, \mathrm{Co}, \mathrm{Ni}, \mathrm{Np}$ \\
2 & $\mathrm{~B}$ & Aluminum & $\mathrm{Ag}, \mathrm{Au}, \mathrm{Co}$ \\
3 & $\mathrm{C}$ & Aluminum & $\mathrm{Ag}, \mathrm{Au}, \mathrm{Co}$ \\
4 & $\mathrm{H} 51$ & Aluminum & $\mathrm{HAFMs}: \mathrm{Al}-\mathrm{Li}, \mathrm{Al}-\mathrm{B}, \mathrm{Bc}$ \\
5 & $\mathrm{D}$ & Aluminum & $\mathrm{Ag}, \mathrm{Au}, \mathrm{Co}, \mathrm{Ni}$ \\
\hline \hline
\end{tabular}


slot 1 had a depressive influence on the thermal flux in vial B, adjacent to the gadolinium. Vial $D$ is at maximum distance from $B$ to check for any vertical flux gradients in the capsule.

\subsection{IRRADIATION SCHEDULE}

The request for irradiation of the DOS I package was submitted to RRD on January 10,1992, and approval was received on January 21, 1992. The DOS 1 package was placed in the HB-4-A, key 7, slot 5 position during the fuel change at the end of cycie 304 on January 26, 1992. It was irradiated for the duration of cycle 305, beginning January 30, 1992, and ending February 27, 1992. During this period, the reactor experienced two unplanned shutdowns, one for $6 \mathrm{~min}$ on February 6, 1992, and the other for $5.5 \mathrm{~d}$ beginning February 16 and ending February 21, 1992. The accrued reactor power at $85 \mathrm{MW}$ was $1875.46 \mathrm{MWd}$. Figure 6 is a schematic depiction of the power-time history. Further details are on file with the authors or can be obtained from the HFIR operations logbooks.

The DOS 1 capsule was recovered from the reactor on Sunday, March 1, 1992, at which time it gave an exposure reading of $25 \mathrm{mR}$ at contact.

\subsection{DISASSEMBLY OF CAPSULE}

On Monday, March 2, 1992, the DOS 1 capsule was transferred to cell 10 in Building 3525. On Tuesday, March 3, 1992, the front cover of the capsule was freed by milling off the welds along the protruding edges of the cover plate. The upper section of the dosimeter block was removed, and it was reaffirmed that the correct vials were in their correct slots in correct orientation with respect to the body bail. The vials were lifted from their slots individually with tweezers and placed in plastic bags. The bags were transferred from the hot cell to an open bench top where the four aluminum-wrapped vials were opened by hand, and the individual monitors were placed in pre-labelled plastic bottles, ready for gamma counting. The HAFM vial was shipped intact to Rockwell International Corporation.

\section{MEASUREMENTS AND RESULTS}

\subsection{RADIOACTIVATION MEASUREMENTS - METHODOLOGY}

Gamma emissions from the radioactivated wires were measured in the neutron activation laboratory at the HFIR. Several spectrometers were utilized, with counting geometries as listed in Table 3. The germanium detectors in the spectrometers are calibrated with standards 
ORNL-DWG 92M-13827

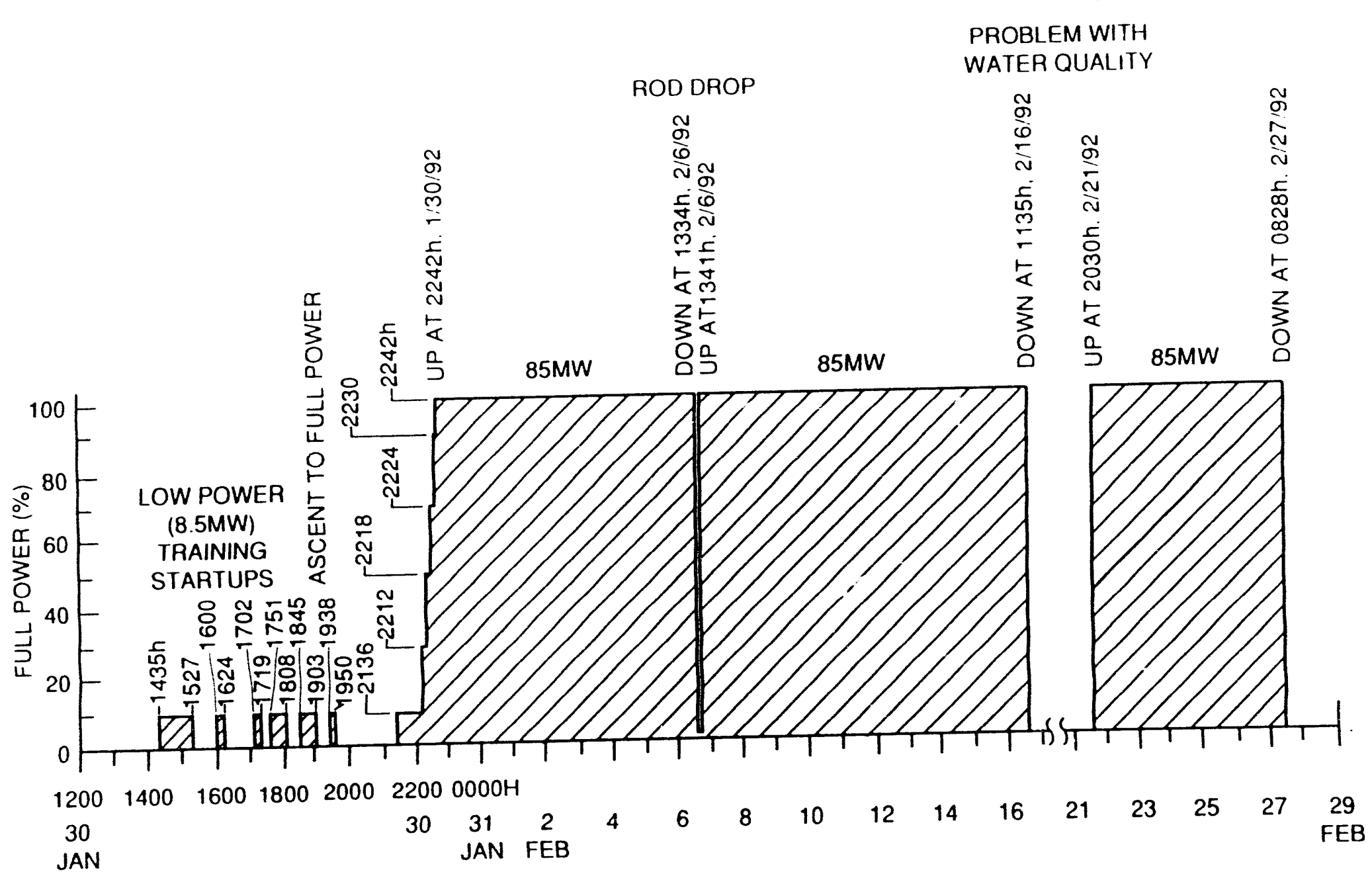

Fig. 6. Schematic representation of the power-time history of Hot Flux Isotope Reactor cycle No. 305. 
Table 3. Gamma-counting conditions for the DOS 1 fux monitors

\begin{tabular}{cccc}
\hline \hline Monitor & Detector & Counting Geometry & Date Counted \\
\hline A-Au & 3 & 150 & $03 / 06 / 92$ \\
B-Au & 4 & 150 & $03 / 06 / 92$ \\
C-Au & 1 & 150 & $03 / 06 / 92$ \\
D-Au & 3 & 150 & $03 / 06 / 92$ \\
A-Np & 4 & 150 & $03 / 06 / 92$ \\
A-Ag & 3 & 80 & $03 / 06 / 92$ \\
B-Ag & 4 & 80 & $03 / 09 / 92$ \\
C-Ag & 3 & 80 & $03 / 09 / 92$ \\
D-Ag & 4 & 80 & $03 / 09 / 92$ \\
A-Ni & 3 & 80 & $03 / 09 / 92$ \\
D-Ni & 4 & 80 & $03 / 09 / 92$ \\
A-Co & 3 & 80 & $03 / 10 / 92$ \\
B-Co & 4 & 80 & $03 / 10 / 92$ \\
C-Co & 4 & 80 & $03 / 10 / 92$ \\
D-Co & 4 & 80 & $03 / 10 / 92$ \\
\hline
\end{tabular}


traceable to the National Institute of Standards and Technology (NIST). Periodic quality control checks are made (daily, when making measurements) to verify that the efficiencies of the particular counting geometry are correct and that all components of the spectroscopy system are functioning correctly. Calibrations are performed with weighted portions of a solution of mixed radionuclides, designated QCY.48, produced and sold every 6 months by Amersham International, plc. Appendix E is a copy of the specification sheet of QCY.48. The daily quality control check is made with a ${ }^{60} \mathrm{Co}$ source that was purchased from Amersham and is traceable to NIST. The activity determined from this source is allowed to differ from the specified value by no more than $5 \%$. If the observed difference exceeds this value, measurements must cease until the error is corrected. Caliurations of the energy scale of the spectrometer systems are made with a sample of ${ }^{232} \mathrm{U}$ that emits gamma rays with energies in the range 238 to $2614 \mathrm{keV}$.

\subsection{RADIOACTIVATION DATA}

The measured activities per unit mass, and the computed activities estimated using the calculated spectrum for key 7 , position 5 , are given in Table 4 . The calculated spectrum is available in Appendix C. The radioactivation data in Table 4 are grouped by monitor material. Within the groups, specific monitors from different locations in the irradiation capsule are listed from vial A (slot 1 at top of capsule) through vial D (slot 5 at bottom of capsule). This arrangement permits a rapid visual comparison of the data to detect any nonuniformity of neutron flux field from top to bottom of the capsule and to identify any inconsistencies within the groups. The ratio of computed-to-measured (C/M) activity also flags any deviants. In a uniform flux field, the activities of the unshielded thermal neutron monitors $B, C$, and $D$ in a material group should be similar to each other and should be considerably higher than the value for the gadolinium-shielded wire from slot $\mathrm{A}$. A perusal of Table 4 shows that the data for all the $\mathrm{Ag}$ and Co wires meet these criteria; those for some of the Au wires do not. The activity measured on the supposedly unshicided B-Au wire is much lower than for the other two unshielded C-Au and D-Au wires and is considerably less than for the supposedly shielded $A u$ wire. Obviously, there has been an inadvertent switch in the Au wires; the one labelled B-Au must really be $\Lambda$ - $\mathrm{Au}$. Also, the other three $A u$ wires have lower activities than expected, as evidenced by their high $\mathrm{C} / \mathrm{M}$ ratios. The half-life of the ${ }^{198} \Lambda \mathrm{u}$ isotope is short, only $2.7 \mathrm{~d}$, and by the time the errors were recognized, it was too late to make repeat measurements to resolve 
Table 4. Activities of flux monitors

(A sample date of 2/27/92 at 08:28 was used in all cases.)

\begin{tabular}{|c|c|c|c|c|c|c|}
\hline Sample Id & $\begin{array}{l}\text { Cover } \\
\text { Material }\end{array}$ & Nuclide & $\begin{array}{c}\text { Measured } \\
\text { Ac'.ivity, M } \\
(\mathrm{Bq} / \mathrm{g})\end{array}$ & $\begin{array}{l}\text { Error } \\
1 \text { sigma }\end{array}$ & $\begin{array}{c}\text { Calcliated } \\
\text { Activity, C } \\
(\mathrm{Bq} / \mathrm{g})\end{array}$ & $\begin{array}{c}\text { Ratio } \\
\mathrm{C} / \mathrm{M}\end{array}$ \\
\hline $\mathrm{A}-\mathrm{Ag}$ & Gd & $\mathrm{Ag}-110 \mathrm{~m}$ & $2.54 \mathrm{E} 4$ & $1 \mathrm{E} 2$ & $1.40 \mathrm{E} 4$ & 0.55 \\
\hline B-Ag & Al & Ag-110m & $1.38 \mathrm{E} 5$ & $2 \mathrm{E} 2$ & $1.82 \mathrm{E} 5$ & 1.32 \\
\hline $\mathrm{C}-\mathrm{Ag}$ & Al & $\mathrm{Ag}-110 \mathrm{~m}$ & $1.48 \mathrm{E} 5$ & $5 \mathrm{E} 2$ & $1.82 \mathrm{E} 5$ & 1.23 \\
\hline D-Ag & $\mathrm{Al}$ & $\mathrm{Ag}-110 \mathrm{~m}$ & $1.54 \mathrm{E} 5$ & $6 \mathrm{E} 2$ & $1.82 \mathrm{E} 5$ & 1.18 \\
\hline $\mathrm{A}-\mathrm{Au}$ & $\mathrm{Gd}$ & $A u-198$ & $4.17 \mathrm{E} 7$ & $1 \mathrm{E5}$ & $5.84 \mathrm{E} 6$ & 0.14 \\
\hline $\mathrm{B}-\mathrm{Au}$ & Al & Au-198 & $8.26 \mathrm{E} 6$ & $5 \mathrm{E} 4$ & 8.59E7 & 10.4 \\
\hline $\mathrm{C}-\mathrm{Au}$ & $\mathrm{Al}$ & $\mathrm{Au}-198$ & $5.90 \mathrm{E} 7$ & $2 \mathrm{E} 4$ & $8.59 \mathrm{E} 7$ & 1.46 \\
\hline$D-A u$ & Al & Au-198 & $5.52 \mathrm{E} 7$ & $1 \mathrm{E} 5$ & 8.59E7 & 1.56 \\
\hline $\mathrm{A}-\mathrm{Co}$ & $\mathrm{Gd}$ & Co-60 & $2.59 \mathrm{E} 4$ & $1 \mathrm{E} 2$ & $2.35 \mathrm{E} 4$ & 0.91 \\
\hline B-Co & Al & Co -60 & $5.53 \mathrm{E} 5$ & $1 \mathrm{E} 3$ & $7.58 \mathrm{E} 5$ & 1.37 \\
\hline C-Co & Al & Co-60 & $5.77 \mathrm{E} 5$ & $2 \mathrm{E} 3$ & $7.58 \mathrm{E} 5$ & 1.31 \\
\hline D-Co & Al & Co- 60 & $6.11 \mathrm{E} 5$ & $2 \mathrm{E} 3$ & $7.58 \mathrm{E} 5$ & 1.24 \\
\hline $\mathrm{A}-\mathrm{Ni}$ & $\mathrm{Gd}$ & Co-58 & $5.18 \mathrm{E} 4$ & $2 \mathrm{E} 2$ & $4.24 \mathrm{E} 4$ & 0.79 \\
\hline $\mathrm{D}-\mathrm{Ni}$ & Al & Co-58 & $5.38 \mathrm{E} 4$ & $2 \mathrm{E} 2$ & $4.24 \mathrm{E} 4$ & 0.82 \\
\hline A-Np & Gd & $\mathrm{Ba}-140$ & 3.99E5 & $1.4 \mathrm{E} 5$ & $1.97 \mathrm{E} 4^{*}$ & 0.049 \\
\hline
\end{tabular}

*Includes fission yield 
the situation. Because of these irregularities, all of the Au data are excluded from further analysis.

Among the remaining thermal flux monitors, $\mathrm{Ag}$ and $\mathrm{Co}$, there is consistency, and a general trend of slowly increasing activity from vials B (slot 2 near the top of the capsule) through $\mathrm{C}$ to D (slot 5 at the bottom of the capsule) is discernible. Whether this pattern is due to the presence of the gadolinium vial in slot 1 , or to a genuine nonuniformity of thermal flux field, is not clear.

With regard to the fast flux monitors, the activity of the A-Ni wire, irradiated in the gadolinium vial, should not be affected by the gadolinium. This seems to be verified by the close correspondence of the activities of the $\mathrm{A}-\mathrm{Ni}$ wire and the unshielded $\mathrm{D}-\mathrm{Ni}$ wire from slot 5. The very slight difference in the two values indicates that there is little or no gradient in fast flux from top to bottom of the capsule. The extremely low $\mathrm{C} / \mathrm{M}$ ratio for the shielded $\mathrm{Np}$ fission monitor indicates a problem there, which will be discussed in detail later in this report.

\subsection{DETERMINATION OF NEUTRON FLUXES FROM RADIOACTIVATION DATA}

Neutron fluxes were derived from the nuclide activities via the procedures described in the following ASTM standard practice manuals:

E 261: Practice for Determining Neutron Fluence Rate. Fluence, and Spectra by Radioactivation Techniques.

E 262: Test Method for Determining Thermal Neutron Reaction and Fluence Ratu's by Radioactive Techniques.

E 264: Test Method for Measuring Fast-Neutron Reaction Rates by Radioactivation of Nickel.

1: 481: Test Method for Measuring Neutron Fluence Rate by Radioactivation of Cohalt and Silver.

E 705: Test Method for Measuring Reaction Rates by Radioactivation of Neptunium-237.

E 944: Guide for Application of Nentron Spectrum Adjustment Methods in Reactor Surveillance.

The relevant data are presented in Table 5. 
Table 5. Neutron fluxes obtained from the radioactivation monitors

\begin{tabular}{|c|c|c|c|c|c|c|c|c|c|c|}
\hline $\begin{array}{l}\text { Slot/ } \\
\text { vial }\end{array}$ & Reaction $(1)$ & $\begin{array}{l}\text { Product } \\
\text { nuclide } \\
\text { activity } \\
\text { a removal } \\
\text { Arof } \\
(B q / \mathrm{mg})\end{array}$ & $\begin{array}{c}N_{0} \\
\text { (atom/mg) }\end{array}$ & $\begin{array}{l}\text { Disinte- } \\
\text { gration } \\
\text { rate } \\
\lambda \\
\left(\mathrm{s}^{-1}\right)\end{array}$ & $\begin{array}{c}\text { Fission } \\
\text { rield } \\
y\end{array}$ & $\begin{array}{l}\text { Saturation } \\
\text { Factor } \\
\text { SF }\end{array}$ & $\begin{array}{l}\text { Reaction } \\
\text { Rate Per } \\
\text { Target } \\
\text { Atom } \\
\text { A SAT }\end{array}$ & $\begin{array}{l}\text { Cross } \\
\text { Section } \\
\sigma \\
\text { (barns) }\end{array}$ & $\begin{array}{l}\text { Meutron } \\
\text { flux } \\
\varphi_{1}^{(2)} \\
\left(n \cdot m^{-2} \cdot s^{-1}\right)\end{array}$ & $\begin{array}{l}\text { Meutron } \\
\text { Flux } \\
\varphi_{2}^{(3)} \\
\left(n \cdot \mathrm{m}^{-2} \cdot \mathrm{s}^{-1}\right)\end{array}$ \\
\hline $1 / A$ & 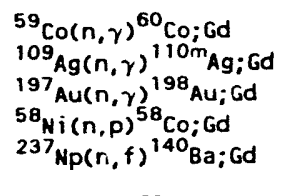 & $\begin{array}{l}2.59 E 1 \\
2.54 E 1 \\
4.17 E 4 \\
5.18 E 1 \\
3.99 E 2\end{array}$ & $\begin{array}{l}1.022 E 19 \\
2.690 E 18 \\
3.057 E 18 \\
7.004 E 18 \\
2.541 E 18\end{array}$ & $\begin{array}{l}4.169 E-9 \\
3.211 E-8 \\
2.976 E-6 \\
1.133 E-7 \\
6.291 E-7\end{array}$ & $5.489 E-2$ & $\begin{array}{l}7.558 E-3 \\
5.606 E-2 \\
8.167 E-1 \\
1.792 E-1 \\
5.740 E-1\end{array}$ & $\begin{array}{l}3.353 E-16 \\
1.685 E-16 \\
1.670 E-14 \\
4.127 E-17 \\
4.984 E-15\end{array}$ & $\begin{array}{l}37.45 \\
4.10 \\
98.80 \\
0.272^{(4)} \\
1.98^{(4)}\end{array}$ & $\begin{array}{l}2.300 E 12 \\
2.110 E 12 \\
1.517 E 12 \\
2.517 E 13\end{array}$ & $\begin{array}{l}2.310 \mathrm{E} 12 \\
1.505 \mathrm{E} 12\end{array}$ \\
\hline $2 / B$ & $\begin{array}{l}{ }^{59} \mathrm{Co}(n, \gamma){ }^{60} \mathrm{Co} \\
{ }^{109} \mathrm{Ag}(n, \gamma){ }^{110 m_{\mathrm{Ag}}} \\
197_{\mathrm{Au}(n, \gamma)}{ }^{198} \mathrm{Au}\end{array}$ & $\begin{array}{l}5.53 E 2 \\
1.38 E 2 \\
8.26 E 3\end{array}$ & & & & & $\begin{array}{l}7.159 E-15 \\
9.151 E-16 \\
3.308 E-15\end{array}$ & & $\begin{array}{l}2.440 E 12 \\
2.160 E 12\end{array}$ & $2.407 E 12$ \\
\hline $3 / C$ & $\begin{array}{l}{ }^{59} \mathrm{Co}(n, \gamma)^{60} \mathrm{Co} \\
{ }^{109} \mathrm{Ag}(n, \gamma)^{110 m_{\mathrm{Ag}}} \\
{ }^{197_{\mathrm{Au}(n, \gamma)^{198}}}{ }^{\mathrm{Au}}\end{array}$ & $\begin{array}{l}5.77 E 2 \\
1.48 E 2 \\
5.90 E 4\end{array}$ & & & & & $\begin{array}{l}7.470 E-15 \\
9.814 E-16 \\
2.363 E-14\end{array}$ & & $\begin{array}{l}2.540 E 12 \\
2.310 E 12\end{array}$ & $2.539 E 12$ \\
\hline $5 / 0$ & $\begin{array}{l}{ }^{59} \mathrm{Co}(n, \gamma)^{60}{ }^{\mathrm{Co}} \\
{ }^{109} \mathrm{Ag}(n, \gamma){ }^{110 m_{\mathrm{Ag}}} \\
\left.{ }_{197} \mathrm{Au}(n, \gamma)\right)^{198} \mathrm{Au} \\
58_{\mathrm{Ni}(n, p)}{ }^{58} \mathrm{Co}\end{array}$ & $\begin{array}{l}6.11 E 2 \\
1.54 E 2 \\
5.52 E 4 \\
5.38 E 1\end{array}$ & & & & & $\begin{array}{l}7.910 E-15 \\
1.021 E-15 \\
2.211 E-14 \\
4.286 E-17\end{array}$ & & $\begin{array}{l}2.700 \mathrm{E} 12 \\
2.410 \mathrm{E} 12 \\
1.576 \mathrm{E} 12\end{array}$ & $\begin{array}{l}2.671 E 12 \\
1.572 E 12\end{array}$ \\
\hline
\end{tabular}

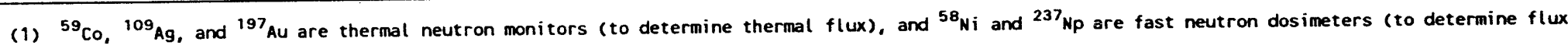

(2) Using methods in ASTM E-261-90 and ASTM E-262-90 to determine flux from radioactivation measurements.

(3) Using method in ASTM E-944-89 to determine flux from radioactivation measurements (Method rejected ${ }^{237^{N p}}$ and ${ }^{197}$ Au dosimeters).

(4) Spectral averaged cross section for neutrons with energies greater than $1 \mathrm{MeV}$, using calculated spectrum for key 7 , position 5. 
The reaction rate per target atom, $\mathrm{A}_{\mathrm{SAT}}$, was calculated as follows:

$$
A_{S A T}=\frac{A_{T O R}}{N_{o} Y \sum_{j} P_{j}\left(1-e^{-\lambda T_{j}}\right) e^{-\lambda\left(T-t_{j}\right)}},
$$

where:

$\mathrm{A}_{\mathrm{SAT}}=$ reaction rate per target atom (column 8, Table 5);

$\mathrm{N}_{\mathrm{o}} \quad=$ number of target atoms per mg in dosimeter (column 4, Table 5);

$\mathrm{Y} \quad=$ fission yield (coiumn 6, Table 5);

$\mathrm{P}_{\mathrm{j}} \quad=$ fraction of full power during operating period $\mathrm{j}$;

$\mathrm{T}_{\mathrm{j}} \quad=$ length of time for irradiation interval $\mathrm{j}$;

$\mathrm{T} \quad=$ time from beginning of irradiation to time of removal;

$\mathrm{t}_{\mathrm{j}} \quad=$ elapsed time from beginning of irradiation to end of time interval $\mathrm{j}$;

$\lambda=$ decay constant of the product nuclide (column 5, Table 5);

$\mathrm{A}_{\text {TOR }}=$ product nuclide activity at time of removal (column 3, Table 5).

The saturation factor. SF (column 7, Table 5), is defined as:

$$
S F=\sum_{j} P_{j}\left(1-e^{-\lambda T_{j}}\right) e^{-\lambda\left(T-t_{j}\right)}
$$

The effective threshold cross sections for the nickel and neptunium monitors were obtained from:

$$
\sigma_{E>1}=\frac{\int_{0}^{\infty} \sigma(E) \varphi(E) d E}{\int_{1}^{\infty} \varphi(E) d E},
$$

where:

$\sigma_{E>1}=$ effective threshold cross section greater than $1 \mathrm{MeV}$ for the assumed spectrum:

$\varphi(E)=$ calculated spectrum for key 7 , position 5 ;

$\sigma(E)=$ differential cross section for the reaction.

The values are given in column 9, Table 5 .

The bare saturated activities for cobalt and silver in the gadolinium vial at location 1/A were determined by extrapolation of the data for the bare wires from slots $2 / B, 3 / C$, and 5/D. The values obtained were $6.732 \times 10^{-15}$ for cobalt and $8.952 \times 10^{-16}$ for silver. It is recognized that these extrapolations could contain discrepancies due to flux depression and self-shielding corrections. The gold data had inconsistencies that excluded them from analysis. The 
gadolinium ratios for cobalt and silver were 20.1 and 5.31, respectively. The assumption was made that the gadolinium ratios for cobalt and silver were the same at all positions. The thermal cross sections for cobalt and silver were obtained from ASTM E-262 and E-481, respectively. The true thermal flux, assuming a Maxwellian distribution, is calculated as follows:

$$
\varphi_{\mathrm{th}}=\frac{\mathrm{A}_{\mathrm{B}}}{\mathrm{G}_{\mathrm{th}} \mathrm{g} \sigma_{0}} \times \frac{\mathrm{R}-1}{\mathrm{R}} \times\left(\frac{4 \mathrm{~T}}{\pi \mathrm{T}}\right)^{1 / 2},
$$

where:

$$
\begin{aligned}
& \varphi_{\mathrm{th}}=\text { true thermal flux, } \\
& \mathrm{A}_{\mathrm{B}}=\text { reaction rate of bare monitor, } \\
& \mathrm{G}_{\mathrm{th}}=\text { thermal self-shielding factor, } \\
& \mathrm{g}=\text { departure from } 1 / \mathrm{v} \text { cross section in the thermal region, } \\
& \mathrm{R}=\text { gadolinium ratio, } \\
& \mathrm{T}_{\mathrm{o}}=293.4 \mathrm{~K}, \\
& \mathrm{~T}=323.4 \mathrm{~K} \text { for HFIR surveillance locations, } \\
& \sigma_{0}=\text { thermal }\left(2200 \mathrm{~m} \cdot \mathrm{s}^{-1}\right) \text { neutron activation cross section. }
\end{aligned}
$$

The $g$ values for cobalt and silver are 1.000 and 1.005 , respectively. The $G_{t h}$ value for cobalt (0.5-mm-diam wire) is 0.9 and that for silver $(0.25$-mm-diam wire) is 0.984 .

\section{$\therefore 4$ RESULTS FPOM THE RADIOACTIVATION MONITORS}

The values for the neutron fluxes in column 11 of Table 5 were obtained from the adjustment code LSL-M2 using the transport calculations and the measured values. Those in column 10 were obtained using the methods in ASTM E-261-90 and E-262-90. There is good and consistent agreement in the thermal neutron fluxes derived from the $\mathrm{Ag}$ and Co monitors. The tendency for increasing radioactivity from top to bottom of the capsule is reflected by the increasing thermal flux from slot 1 to slot 5 . The mean thermal flux is $2.4 \times 10^{12} \mathrm{n} \cdot \mathrm{m}^{-2} \cdot \mathrm{s}^{-1}$. The mean fast flux from the Ni monitors is $1.5 \times 10^{12} \mathrm{n}_{1} \cdot \mathrm{n}^{-2} \cdot \mathrm{s}^{-1}(>1 \mathrm{MeV})$. The fast flux derived from the $\mathrm{Np}$ fission monitor is $2.6 \times 10^{13} \mathrm{n} \cdot \mathrm{m}^{-2} \cdot \mathrm{s}^{-1}$, a factor of 17 times larger than that from the Ni monitors. 


\subsection{HELIUM MEASUREMENTS ON HAFMS - METHODOLOGY}

Vial H51 containing the HAFMS was opened at Rockwell International Corpation, and the helium contents of the monitors were measured by vaporizing pieces of them and performing gas mass spectroscopy according to ASTM E910-89 in ref. 9. An outline of the procedure is:

Each monitor was cut or, in the case of the beryllium, broken into several pieces, which were then etched in acid to remove surface material that may have been affected due to contamination or to $\alpha$ recoils into and out of the material. This etching step is a standard procedure for irradiated HAFMs. After washing and drying, each piece was carefully weighed and placed in a small, tungsten-wire, electrical resistance heater in a vacuum chamber attached to the mass spectrometer. When the vacuum level was satisfactory, the specimen was rapidly evaporated to release the helium, which was measured in the spectrometer. Calibration was done against a known volume of helium-3 "spiked" into the vacuum chamber immediately prior to sample vaporization. At least two separate pieces of each monitor were measured, and the results were averaged. The helium concentrations are expressed as atomic parts per billion (appb). To obtain a neutron flux, the helium concentrations are divided by an appropriate, spectral-averaged helium production cross section and by the neutron exposure period.

\subsection{HAFM DATA}

A full description of the helium analyses of the wires from the $\mathrm{H} 51$ vial is available in a letter report from Rockwell International Corporation, dated May 20, 1992 (RI ref. 92RC00784). A Nuclear Ragulatory Guide (NUREG) report is in preparation. The salient data are presented in Table 6. Helium analyses were performed on two pieces of each monitor. For the Be, the results were higher than expected from consideration of the estimated fast flux, so two further pieces were cut and analyzed. These extra two pieces were also heavily etched to forestall any question of surface contamination effects. The helium results were unchanged by the deep etch, indicating that the helium is distributed through the bulk of the Be, not in the surface layers. The average helium concentration for each of the monitors was used to determine the neutron fluxes.

For the two thermal flux HAFMs, Li and B, the helium production cross sections were taken to be the well-established thermal neutron absorption cross sections of 942 and 3838 barns, respectively. Using these values, the thermal flux from the Li monitor is $2.29 \times$ 
Table 6. Helium concentrations measured for the helium accumulation fluence monitors, and corresponding neutron fluxes

\begin{tabular}{|c|c|c|c|c|c|c|c|c|c|}
\hline \multirow[b]{2}{*}{ Specimen 10} & \multirow{2}{*}{$\begin{array}{l}\text { Helium (a) } \\
\text { Production } \\
\text { Reaction }\end{array}$} & \multirow{2}{*}{$\begin{array}{l}\text { Specimen } \\
\text { Mass" } \\
\text { (mg) }\end{array}$} & \multirow{2}{*}{$\begin{array}{l}\text { Measured } \\
4 \text { He } \\
\left(10^{11} \text { atoms }\right)\end{array}$} & \multicolumn{3}{|c|}{$\begin{array}{l}\text { Hel ium Concentration } \\
\text { (appo) }\end{array}$} & \multirow{2}{*}{$\begin{array}{l}\text { Cross } \\
\text { Section } \\
\text { (barns) }\end{array}$} & \multicolumn{2}{|c|}{$\begin{array}{l}\text { Neutron } f(\mu x) \\
\left(n \cdot m^{-2} \cdot s^{-1}\right)\end{array}$} \\
\hline & & & & Measured ${ }^{b}$ & Corrected & Average & & Thermal & Fast \\
\hline $\begin{array}{r}\text { HS1-ALLi-A } \\
-B\end{array}$ & ${ }^{6} \mathrm{Li}(n, \alpha)^{3} H$ & $\begin{array}{l}0.964 \\
0.965\end{array}$ & $\begin{array}{l}2.601 \\
2.589\end{array}$ & $\begin{array}{l}388.7 \\
386.5\end{array}$ & $\begin{array}{l}491.6 \\
409.3\end{array}$ & $410 \pm 2$ & 942 & 2.29E12 & \\
\hline $\begin{array}{r}H 51-A 1 B-A \\
-B\end{array}$ & ${ }^{10} B(n, \alpha)^{7} L i$ & $\begin{array}{l}1.346 \\
1.357\end{array}$ & $\begin{array}{l}1.170 \\
1.179\end{array}$ & $\begin{array}{l}1628 \\
1628\end{array}$ & $\begin{array}{l}1657 \\
1657\end{array}$ & $1657 \pm 0$ & 3838 & $2.26 E 12$ & \\
\hline $\begin{array}{r}\text { H51-Be-A } \\
-C \\
-D \\
-E\end{array}$ & $\begin{array}{l}\text { Several: } \\
9_{B e(n, a)}{ }^{6} \mathrm{He}(a+2 n) \\
9_{B e(n, 2 n)^{8}} \operatorname{Be}(2 \alpha) \\
9_{B e(n, d) 2 \alpha}\end{array}$ & $\begin{array}{l}2.889 \\
2.150 \\
0.520^{\circ} \\
0.486^{\circ}\end{array}$ & $\begin{array}{l}5.409 \\
4.117 \\
0.974 \\
0.923\end{array}$ & $\begin{array}{l}2.802 \\
2.866 \\
2.803 \\
2.842\end{array}$ & $\begin{array}{l}2.750 \\
2.814 \\
2.751 \\
2.790\end{array}$ & $2.78 \pm 0.03$ & $0.653^{f}$ & & $2.23 E 13$ \\
\hline
\end{tabular}

a Mass uncertainty is $\pm 1 \mu g$.

c Hel ium concentrations in the beryllium specimens have been corrected for measured residual helium $(0.05 \pm 0.03$ appb) and for helium generation ( 0.002 appb) from an 8.9+2.0 wt. ppm boron impurity. Helium concentrations in the $\mathrm{Al}-\mathrm{Li}$ and $\mathrm{Al}-\mathrm{B}$ have been corrected for neutron self-shielding in the wire material. The correction values are 5.97 for $\mathrm{Al}-\mathrm{LI}$ and $\mathbf{1 . 8 \%}$ for Al-B.

d Mean and standard deviation (10) of replicate analyses.

- New specimens cut from original "Be-B" specimen after additional etching (see text).

f Calculated from ENDF/B-V gas production file using estimated key 7, position 5 spectrum for E>1Mey. 
$10^{12} \mathrm{n} \cdot \mathrm{m}^{-2} \cdot \mathrm{s}^{-1}$; that from the $\mathrm{B}$ monitor is $2.26 \times 10^{12} \mathrm{n} \cdot \mathrm{m}^{-2} \cdot \mathrm{s}^{-1}$. These fluxes are very close to those derived from the thermal neutron radioactivation monitors.

For the fast flux HAFM, Be, the appropriate helium production cross section for $\mathrm{E}>1 \mathrm{MeV}$ was calculated to be 0.653 barns from the ENDF/B-V gas production file using the estimated key 7 , position 5 spectrum. This yielded a fast flux of $2.23 \times 10^{13} \mathrm{n} \cdot \mathrm{m}^{-2} \cdot \mathrm{s}^{-1}$. This value of fast flux is a factor of 15 times higher than that obtained from the Ni activation wires, and is very close to that from the $\mathrm{Np}$ fission monitor.

\section{DISCUSSION}

The goal of this dosimetry experiment was to obtain a definitive measurement of the flux of thermal neutrons at the key 7 surveillance site. This measured flux would assist the pressure vessel embrittlement studies and would provide a benchmark for calculations of thermal flux at the key 7 , and other, surveillance sites. The data presented here satisfy those objectives. Consistent results were obtained from eight individual radioactivation monitor wires and from two HAFMs. They are summarized in Table 7, together with the recent, estimated thermal flux, and with a tentative measurement from ${ }^{60} \mathrm{Co}$ activity made on a piece of stainless steel removed from the key 7 , position 6 location in 1986. For position 5, measured in this experiment, the average thermal flux for the eight activation wires is $2.4 \times 10^{12} \mathrm{n} \cdot \mathrm{m}^{-2} \cdot \mathrm{s}^{-1}$. This includes a seeming increase in flux of about $17 \%$ from top to bottom of the capsule. The average flux for the $\mathrm{Li}$ and B HAFMs is $2.3 \times 10^{12} \mathrm{n} \cdot \mathrm{m}^{-2} \cdot \mathrm{s}^{-1}$. The agreement between the radioactivation monitors and the HAFMs is good. The calculated thermal flux for position 5 is $3.7 \times$ $10^{12} \mathrm{n} \cdot \mathrm{m}^{-2} \cdot \mathrm{s}^{-1}$, somewhat higher than the measured values. as indicated by the $\mathrm{C} / \mathrm{M}$ ratios. The data for position 5 are also in acceptable agreement with the earlier, tentative measurement made in position 6 and with the $\mathrm{C} / \mathrm{M}$ ratio for that measurement. Taken together, these data leave no doubt about the value of the thermal neutron flux at positions 5 and 6 in the key 7 surveillance site, and they affirm that the recent calculations are of the correct order. Closer correspondence between measured and calculated thermal fluxes should require only a small adjustment in the calculations.

These thermal flux data are very pertinent to the HFIR pressure vessel embrittlement studies. One proposed model for the accelerated embrittlement is dependent on a high thermalto-fast flux ratio at the vessel. ${ }^{3}$ This dosimetry experiment shows that the thermal-to-fast flux 
Table 7. Summary of neutron flux measurements and recent calculated fluxes at the key 7 surveillance site

\begin{tabular}{|c|c|c|c|c|c|c|c|}
\hline \multirow[b]{2}{*}{ Reaction } & \multirow[b]{2}{*}{$\begin{array}{l}\text { Meutron } \\
\text { Energy } \\
\text { Range }\end{array}$} & \multicolumn{5}{|c|}{ flux at Key 7 site $\left(n \cdot m^{-2} \cdot s^{-1}\right)$} & \multirow[b]{2}{*}{$\begin{array}{l}\text { Ratio } \\
\text { Meas./ } \\
\text { colc. }\end{array}$} \\
\hline & & $\begin{array}{l}1992 \\
\text { Meas. } \\
\text { Pos. } 5\end{array}$ & $\begin{array}{l}1992 \\
\text { Calc. } \\
\text { Pos. } 5\end{array}$ & $\begin{array}{l}\text { Ratio } \\
\text { Meas.f } \\
\text { calc. }\end{array}$ & $\begin{array}{l}1986 \\
\text { Meas. } \\
\text { Pos. } 6\end{array}$ & $\begin{array}{l}1992 \\
\text { Calc. } \\
\text { Pos. } 6\end{array}$ & \\
\hline${ }^{59} \mathrm{Co}(n, \gamma)^{80} \mathrm{Co}$ & $\begin{array}{l}\text { Thermal } \\
\text { (below } \\
\text { Gd cut - } \\
\text { off }\end{array}$ & 2.5 to $2.7 E 12$ & $3.74 E 12$ & -1.50 & 2.91E12 & $4.69 E 12$ & 1.61 \\
\hline${ }^{109} A g(n, \gamma)^{110 m_{A g}}$ & $\begin{array}{l}\text { Thermal } \\
\text { (bel ow } \\
\text { Gd cut - } \\
\text { off) }\end{array}$ & 2.1 to $2.4 E 12$ & & -1.70 & & & \\
\hline HAFM-Li" & Thermal & $2.3 E 12$ & & 1.60 & & & \\
\hline HAFM- $B^{\bullet}$ & Thermal & $2.3 E i 2$ & & 1.60 & & & \\
\hline${ }^{58} \mathrm{Ni}(n, p)^{58} \mathrm{Co}$ & $\begin{array}{l}\text { Fast } \\
(>1 \mathrm{MeV})\end{array}$ & $-1.5 E 12$ & $1.19 E 12$ & 0.793 & $1.80 E 12$ & $1.16 E_{12}$ & 0.644 \\
\hline${ }^{54} \mathrm{Fe}(\mathrm{n}, \mathrm{p}){ }^{54} \mathrm{Mn}$ & $\begin{array}{l}\text { Fast } \\
(>1 \mathrm{MeV})\end{array}$ & & & & $1.89 E 12$ & & 0.613 \\
\hline${ }^{237} \mathrm{Mp}(n, f)^{140} \mathrm{Ba}$ & $\begin{array}{l}\text { Fast } \\
(>1 \mathrm{MeV})\end{array}$ & $2.6 E_{13}$ & & 0.046 & & & \\
\hline HAFH-Be" & $\begin{array}{l}\text { Fast } \\
(>1 \mathrm{MeV})\end{array}$ & $2.2 E 13$ & & 0.054 & & & \\
\hline
\end{tabular}

(a) See Table 6 for HAFM reactions. 
ratio at the key 7 , position 5 site is small, less than two, which is too low to support the model. The model may find application to embrittlement data obtained in the future in the HFIR surveillance program from keys for which the new calculations show high thermal-to-fast flux ratios. ${ }^{7}$ In the meantime, an explanation for the accelerated embrittlement of the key 7 data must be sought elsewhere. A clue may lie in the unusual responses of the fast flux monitors in this dosimetry experiment.

Less attention was paid to fast flux because there has never been good reason to question the fast fluxes that are routinely measured from the stainless steel monitors in the surveillance capsules. They have always been of the expected order, and they agree reasonably well with neutron transport calculations. Thus, the experiment was not required to prove anything for the fast flux; all that was needed was a confirmation of the existing data. Two wires of Ni were thought to be adequate for that purpose. Since there was room available in the experiment, single monitors of $\mathrm{Np}$ and $\mathrm{Be}$ were added to broaden the scope of the previous fast flux dosimetry and to reinforce the $\mathrm{Ni}$ measurements. Seizing that opportunity turned out to be a mixed blessing. Whereas the fast fluxes from the $\mathrm{Ni}$ inonitors appear to verify the previous measurements from stainless steel monitors, the data from the $\mathrm{Np}$ and the Be monitors seem to be equivocal.

$\mathrm{Ni}$ monitors were located in two places in tht: dosimetry capsule, one in the gadolinium vial with the $\mathrm{Np}$ monitor and a group of thermal neutron activation wires, the other in the $\mathrm{D}$ aluminum tube with thermal neutron wires at maximum distance from the gadolinium vial. The gadolinium-shielded $\mathrm{Ni}$ wire recorded a fast flux of $1.5 \times 10^{12} \mathrm{n} \cdot \mathrm{m}^{-2} \cdot \mathrm{s}^{-1}$, in very close agreement with the unshielded $\mathrm{Ni}$ wire which gave a value of $1.6 \times 10^{12} \mathrm{n} \cdot \mathrm{m}^{-2} \cdot \mathrm{s}^{-1}$. Previous measurements from $\mathrm{Ni}$ and $\mathrm{Fe}$ activation in stainless steel monitors had given a flux of $\sim 1.8 \times 10^{12} \mathrm{n} \cdot \mathrm{m}^{-2} \cdot \mathrm{s}^{-1}$ for key 7 . position 6 in 1986 , and the recent calculations for both positions 5 and 6 gave $\sim 1.2 \times 10^{12} \mathrm{n} \cdot \mathrm{m}^{-2} \cdot \mathrm{s}^{-1}$. In stark contrast to all of these values, the $\mathrm{Np}$ fission monitor yielded a fast flux of $2.6 \times 10^{13} \mathrm{n} \cdot \mathrm{m}^{-2} \cdot \mathrm{s}^{-1}$, and the Be HAFM, which was located in a separate aluminum vial between the two Ni wires, indicated a flux of $2.2 \times 10^{13} \mathrm{n} \cdot \mathrm{m}^{-2} \cdot \mathrm{s}^{-1}$.

These discrepancies of factors of 17 and 15 for the $\mathrm{Np}$ and Be fluxes, respectively, with respect to the average for $\mathrm{Ni}$, are highly unusual. A single discrepancy of this size would have been viewed with the greatest suspicion and probably dismissed summarily. But two discrepancies of the same magnitude and the same direction occurring from two different types of monitors, measured by different techniques by independent parties. each without knowledge 
of the other's finding, demanded more respect. A thorough search for errors in the measurements was unrewarding. Repeat helium analyses on the Be were made after heavy etching, as mentioned earlier. and they reproduced the original measurements. The A-Np monitor was remeasured at ORNL by a different person using a different spectrometer, and the reading was confirmed. Next, the A-Np monitor was sent to NIST at Gaithersburg, Maryland, for a further check, together with a new monitor, labelled NIST-Np, from the same source as A-Np. The NIST-Np monitor was irradiated at NIST in a known neutron spectrum, and the activities of it and the A-Np were measured by NIST, then remeasured at ORNL. Agreement in these measurements was found to be within a few percent, testifying that the instruments and calibrations used to obtain the controversial fast flux data from the A-Np monitor were not at fault.

The remote possibility that the A-Np capsule might contain a great deal more $\mathrm{Np}$ than specified was addressed by measuring the activity of ${ }^{233} \mathrm{~Pa}$, a daughter product of ${ }^{237} \mathrm{~Np}$. The A-Np monitor was one of a batch of monitors (batch 83-1) made some years ago, and it was expected that the activities of the ${ }^{237} \mathrm{~Np}$ and ${ }^{233} \mathrm{~Pa}$ would now be equal. The ${ }^{233} \mathrm{~Pa}$ activities of four unused monitors from the batch were measured (see Table 8), from which the mass of ${ }^{237} \mathrm{~Np}$ in each monitor was derived. Comparison with the specified ${ }^{237} \mathrm{~Np}$ masses for the monitors gave a mean ratio of 0.959 . Applying this mean ratio to the derived ${ }^{237} \mathrm{~Np}$ masses for the NIST-Np and the A-Np monitors yielded the specified masses shown in parentheses in column 9 of Table 8 . These agree very closely with the actual, specified ${ }^{237} \mathrm{~Np}$ masses. Clearly, there is no error in the mass of ${ }^{237} \mathrm{~Np}$ in the A-Np monitor, and it is not the cause of the fast flux inconsistency.

The search then turned to the Ni monitors to see if the fast flux discrepancy could be attributed to errors in the $\mathrm{Ni}$ activation data. A sample of the unirradiated source wire was chemically analyzed, and it verified the original composition. The gamma activities of the A-Ni and $\mathrm{D}-\mathrm{Ni}$ monitors were remeasured by three different people at ORNL, in three different laboratories, using three different spectrometers. The spread of the results was $\pm 7 \%$. Therefore, there seems to be no flaw in the $\mathrm{Ni}$ data.

This experiment is the only occasion in which $\mathrm{Np}$ and Be monitors have been irradiated in the spectrum at the HFIR vessel. Monitors of $\mathrm{Ni}, \mathrm{Np}$, and $\mathrm{Be}$ have been exposed together in many other neutron dosimetry experiments elsewhere and have always given complementary results. Indeed, while the DOS 1 experiment was under way, a parallel dosimetry experiment 
Table 8. Determination of mass of ${ }^{237} \mathrm{~Np}$ in $\mathrm{Np}$ monitors, using ${ }^{233} \mathrm{~Pa}$ activities

\begin{tabular}{|c|c|c|c|c|c|c|c|c|c|}
\hline \multirow[b]{2}{*}{$\begin{array}{l}\text { Monitor } \\
\text { Identity }\end{array}$} & \multicolumn{4}{|c|}{ Counting Details } & \multirow{2}{*}{$\begin{array}{c}\text { Pa-233 } \\
\text { Activity, } \\
\text { Bq }\end{array}$} & \multirow{2}{*}{$\begin{array}{l}\text { Derived } \\
\text { Atoms } \\
\text { of } \mathrm{Np}-237\end{array}$} & \multirow{2}{*}{$\begin{array}{l}\text { Derived } \\
\text { We. of } \\
\text { Mp- } 237 \\
\text { mg }\end{array}$} & \multirow{2}{*}{$\begin{array}{l}\text { Specified } \\
\text { wt. of } \\
\text { Np-237. } \\
\text { mg }\end{array}$} & \multirow{2}{*}{$\begin{array}{l}\text { Ratio } \\
\text { Deriv. Wt/ } \\
\text { Specif. Wt }\end{array}$} \\
\hline & Date & Time & $\begin{array}{l}\text { Decec. } \\
\text { Number }\end{array}$ & Geom. & & & & & \\
\hline$\# 3$ & 11-Nov-92 & $10: 20$ & 2 & 111 & $2.14 E 5$ & $2.087 E 19$ & 8.212 & 8.567 & 0.959 \\
\hline$\#$ & 11 -Nov-92 & $08: 27$ & 2 & 111 & $2.06 E 5$ & $2.011 E 19$ & 7.914 & 8.258 & 0.958 \\
\hline \#5 & $11-$ Nov-92 & $11: 47$ & 2 & 111 & $2.10 E 5$ & $2.050 E 19$ & 8.066 & 8.416 & 0.958 \\
\hline$\# 29$ & 10-Nov-92 & $16: 37$ & 2 & 111 & $1.65 E 5$ & $1.604 E 19$ & 6.311 & 6.558 & 0.962 \\
\hline$\# 9$ (NIST) & 10 -Nov-92 & $17: 19$ & 2 & 111 & $2.05 E 5$ & $1.995 E 19$ & 7.852 & $8.219(8.188)$ & $(0.959)$ \\
\hline$\# 9$ (NIST) & $10-$ oct -92 & $16: 12$ & 4 & 150 & $2.10 E 5$ & $2.046 E 19$ & 8.052 & $8.219(8.396)$ & $(0.959)$ \\
\hline$\# 10(A-M p)$ & $24-A p r-92$ & 08.28 & 3 & 150 & $2.02 E 5$ & $1.972 E 19$ & 7.759 & $8.253(8.091)$ & $(0.959)$ \\
\hline$\# 10(A-N p)$ & $06-\operatorname{Mar}-92$ & $11: 13$ & 4 & 150 & $2.11 E 5$ & $2.055 E 19$ & 8.086 & $8.253(8.432)$ & $(0.959)$ \\
\hline
\end{tabular}

all monitors are from Batch Np 83-1, Series $N_{;}$\#29 has no series designation. 
was being run in the target region of the HFIR, using $\mathrm{Ni}, \mathrm{Np}$, and $\mathrm{Be}$ monitors from the same sources as those in DOS 1. Analyses of the target monitors* yielded fast fluxes that were fully compatible from each of the three different monitors. This implies that there is nothing wrong with the monitor materials in the DOS 1 experiment. Since we have found no error in the measurements or procedures, we suggest that the apparent inconsistencies in the fast flux data are real and arise from some peculiarity in the exposure conditions at the key 7 site that affect the $\mathrm{Np}$ and $\mathrm{Be}$ monitors much more than the Ni monitors. To validate this assertion, the experiment should be repeated with emphasis on monitors in the fast regions of the neutron spectrum. To that end, a new dosimetry experiment under the sponsorship of the NRC is now under way at the key 7 , position 5 site and other surveillance locations on the vessel.

\section{NOTE ADDED IN PROOF}

Remec and $\mathrm{Kam}^{10}$ have now obtained results from repeat dosimetry experiments, DOS 2 and DOS 3, at the key 7, position 5 location and other surveillance sites on the HFIR pressure vessel. They fully verify the DOS 1 findings herein. They also provide additional data that have helped identify photonuclear reactions as a major contributor to the inflated fast flux values derived from the reaction product monitors $\mathrm{Np}$ and $\mathrm{Be}$. Radioactivation monitors are relatively insensitive to photonuclear events, and, hence, the $\mathrm{Ni}$ wires give the more reliable fast fluxes in these experiments. The measured magnitude of the discrepancies for the $\mathrm{Np}$ and Be monitors can be accounted for by an exceptionally large ratio of gamma flux to fast neutron flux at the vessel. Transport calculations for gamma fluxes, backed by a special gamma dosimetry experiment, DOS 4 , at the key 7 , position 5 slot, have affirmed that the $\gamma / \mathrm{n}$ flux ratio is $>1000$. This high value is believed to be due primarily to the long water path between the core and the vessel wall, which attenuates the fast neutron flux much more than it does the gamma flux.

It is noted, in closing, that gamma rays will not only boost levels of reaction products in some monitors, they will also cause atomic displacements in the vessel wall that could boost embrittlement there.

${ }^{*}$ S. T. Mahmood, S. Mirzadeh, J. V. Pace, III, and K. Farrell, Neutron Flux Measurements in the HFIR Hydraulic Facility, Oak Ridge National Laboratory report (in preparation). 


\section{CONCLUSIONS}

This first comprehensive dosimetry experiment at a surveillance site, the key 7, position 5 location, on the HFIR pressure vessel shows that:

1. The thermal neutron flux measured on eight radioactivation wires and two HAFMs is $2.4 \times 10^{12} \mathrm{n} \cdot \mathrm{m}^{-2} \cdot \mathrm{s}^{-1}$, which is in fair agreement with a thermal flux of $3.7 \times 10^{12} \mathrm{n} \cdot \mathrm{m}^{-2} \cdot \mathrm{s}^{-1}$ recently estimated from neutron transport calculations.

2. The fast neutron flux $(>1 \mathrm{MeV})$ measured on two standard, radioactivation-type wires of $\mathrm{Ni}$ is $1.5 \times 10^{12} \mathrm{n} \cdot \mathrm{m}^{-2} \cdot \mathrm{s}^{-1}$, which is in fair agreement with a tast flux of $1.2 \times$ $10^{12} \mathrm{n} \cdot \mathrm{m}^{-2} \cdot \mathrm{s}^{-1}$ computed from neutron transport calculations and with earlier measurements made on stainless steel surveillance monitors.

3. Two fast flux monitors, of types that have never before been exposed at the HFIR surveillance sites. both reaction product types, one a fission monitor of ${ }^{237} \mathrm{~Np}$ and the other a HAFM of Be, each yielded a fast flux about 15 times larger than that measured from the $\mathrm{Ni}$ wires.

4. Repeat measurements made in follow-up dosimetry experiments, and transport calculations of gamma ray fluxes. validate the above findings and identify photonuclear reactions caused by a very high ratio of gamma flux to fast neutron flux at the vessel wall as the source of the falsely high fast fluxes derived from the $\mathrm{Np}$ and Be monitors.

\section{ACKNOWLEDGMENTS}

We appreciate the cooperation of Dr. E. D. McGarry of NIST with verification of the Np measurements, Dr. R. W. Hobbs for reactor operations, Ms. Margaret Terrell for secretarial services, Drs. S. T. Mahmood and M. L. Grossbeck for technical reviews of this report.

\section{REFERENCES}

1. R. D. Cheverton, J. G. Merkle, and R. K. Nanstad, eds., Evaluation of HFIR PressureVessel Integrity Considering Radiation Embrittlement, ORNL/TM-10444, Martin Marietta Energy Systems, Inc.. Oak Ridge Natl. Lab., April 1988. 
2. R. K. Nanstad, K. Farrell, D. N. Braski, and W. R. Corwin, "Accelerated Neutron Embrittlement of Ferritic Steels at Low Fluence: Flux and Spectrum Effects," J. Nucl. Mater. 158, 1-6 (1988).

3. L. K. Mansur and K. Farrell, "On Mechanisms by Which a Soft Neutron Spectrum may Induce Accelerated Embrittlement," J. Nucl. Mater. 170, 236-4j (1990).

4. R. E. Stoller and L. K. Mansur, "The Influence of Displacement Rate on Damage Accumulation During the Point Defect Transient in Irradiated Materials," pp. 52-57 in Proceedings of the International Conference on Radiation Materials Science, Ukrainian Academy of Sciences, Kharkov, U.S.S.R., 1990.

5. R. L. Childs, personal ccmmunication to R. K. Nanstad, Oak Ridge Natl. Lab., July 1988.

6. J. V. Pace, III, "Procedure For Calculating the Neutron Flux at the HFIR Pressure Vessel," internal correspondence to W. R. Corwin, Oak Ridge Natl. Lab., Jan. 22, 1992.

7. J. V. Pace, III, C. O. Slater, and M. S. Smith, "Letter Report on Beginning-of-Cycle HFIR Flux/Response Calculations at Keys 2, 4, 5 and 7," Oak Ridge Natl. Lab., July 30, 1992.

8. W. R. Corwin, F. B. Kam, C. A. Baldwin, K. Farrell, F. W. Stallman, F. M. Haggag, and B. M. Oliver, "Letter Report on Results of the HFIR Surveillance Position Neutron Dosimetry Experiments," letter to M. E. Mayfield, Nuclear Regulatory Commission, April 30, 1992.

9. ASTM STD E910-89, "Standard Test Method for Application and Analysis of Helium Accumulation Fluence Monitors for Reaction Vessel Surveillance, E706 (111C)," pp. 527-37 in Annual Book of ASTM Standards, Vol. 12.02, American Society for Testing and Materials. New York, 1992.

10. I. Remec and F. B. Kam, "Neutron Spectra at Different HFIR Pressure Vessel Surveillance Locations." NUREG/CR-6117, ORNL/TM-12484, Martin Marietta Energy Systems, Inc., Oak Ridge Natl. Lab., September 1993. 


\author{
APPENDIX A. EARLY, COMPUTED NEUTRON SPECTRA FOR KEY 7 , \\ POSITIONS 6, 7, AND 8.
}

HEIR KEY 7 LOCATION 6

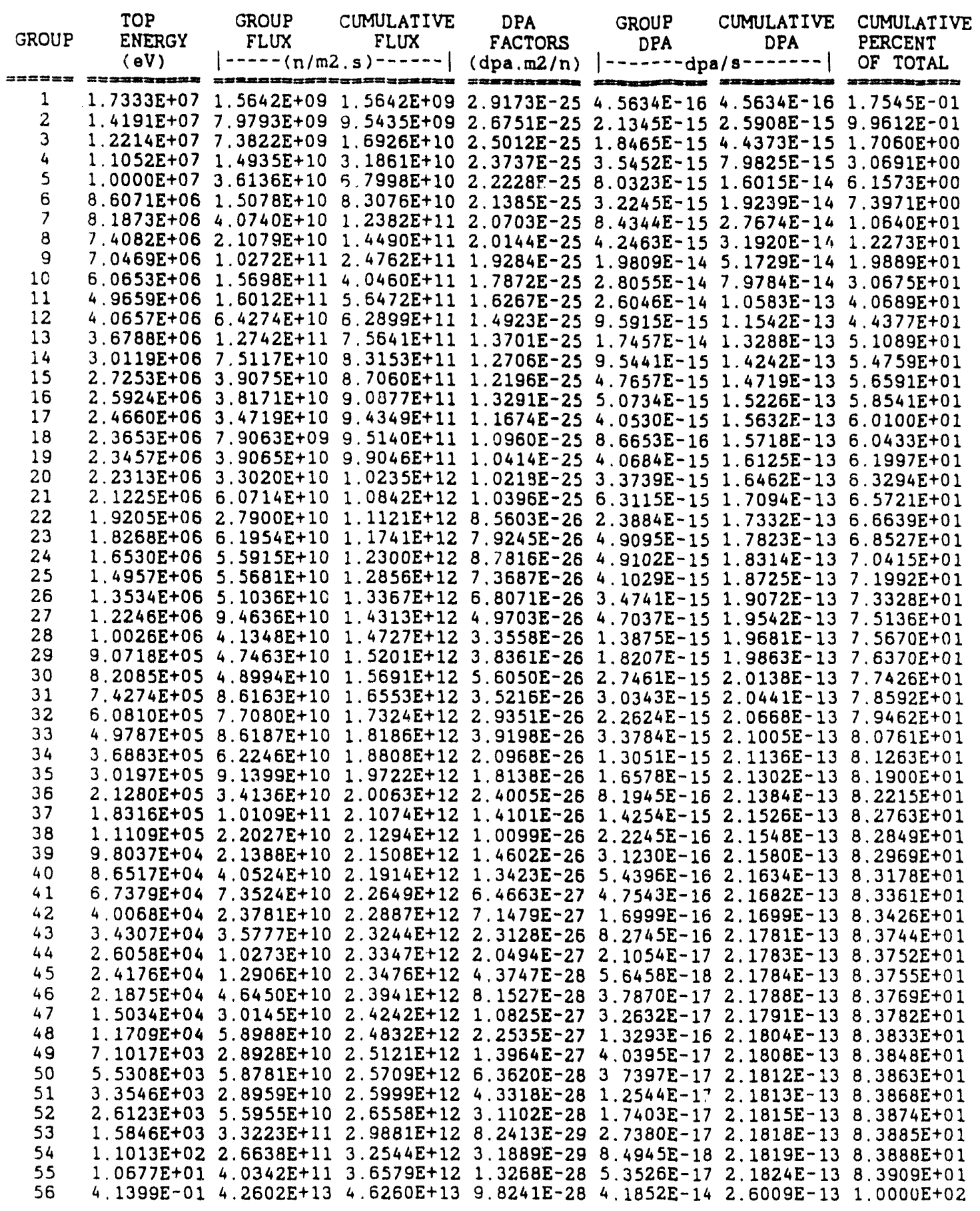


APPENDIX A. Continued.

HFIR KEY 7 LOCATION 7

\begin{tabular}{|c|c|c|c|c|c|c|c|}
\hline ROUP & $\begin{array}{l}\text { TOP } \\
\text { ENERGY } \\
(\mathrm{OV})\end{array}$ & $\begin{array}{c}\text { GROUP } \\
\text { FLUX } \\
---(\mathrm{n} / \mathrm{m} 2\end{array}$ & $\begin{array}{l}\text { CUMULATIVE } \\
\text { FLUX }\end{array}$ & $\begin{array}{c}\text { DPA } \\
\text { FACTORS } \\
(\mathrm{dpa} \cdot \mathrm{m} 2 / \mathrm{n})\end{array}$ & $\begin{array}{r}\text { GROUP } \\
\text { DPA }\end{array}$ & $\begin{array}{l}\text { CUMULATIVE } \\
\text { DPA }\end{array}$ & $\begin{array}{l}\text { CUMULATIVE } \\
\text { PERCENT } \\
\text { OF TOTAL }\end{array}$ \\
\hline $\begin{array}{l}1 \\
2 \\
3 \\
4 \\
5 \\
6 \\
7 \\
8 \\
9 \\
10 \\
11 \\
12 \\
13 \\
14 \\
15 \\
16 \\
17 \\
18 \\
19 \\
20 \\
21 \\
22 \\
23 \\
24 \\
25 \\
26 \\
27 \\
28 \\
29 \\
30 \\
31 \\
32 \\
33 \\
34 \\
35 \\
36 \\
37 \\
38 \\
39 \\
40 \\
41 \\
42 \\
43 \\
44 \\
45 \\
46 \\
47 \\
48 \\
49 \\
50 \\
51 \\
52 \\
53 \\
54 \\
55 \\
56\end{array}$ & $\begin{array}{l}1.7333 E+07 \\
1.4191 E+07 \\
1.2214 E+07 \\
1.1052 E+07 \\
1.0000 E+07 \\
8.6071 E+06 \\
8.1873 E+06 \\
7.4082 E+06 \\
7.0469 E+06 \\
6.0653 E+06 \\
4.9659 E+06 \\
4.0657 \mathrm{E}+06 \\
3.6788 E+06 \\
3.0119 E+06 \\
2.7253 E+06 \\
2.5924 E+06 \\
2.4660 E+06 \\
2.3653 E+06 \\
2.3457 E+06 \\
2.2313 E+06 \\
2.1225 E+06 \\
1.9205 E+06 \\
1.8268 E+06 \\
1.6530 E+06 \\
1.4957 E+06 \\
1.3534 E+06 \\
1.2246 E+06 \\
1.0026 E+06 \\
9.0718 E+05 \\
8.2085 E+05 \\
7.4274 E+05 \\
6.0810 E+05 \\
4.9787 E+05 \\
3.6883 E+05 \\
3.0197 E+05 \\
2.1280 E+05 \\
1.8316 E+05 \\
1.1109 E+05 \\
9.8037 E+04 \\
8.6517 E+04 \\
6.7379 E+04 \\
4.0068 E+04 \\
3.4307 E+04 \\
2.6058 E+04 \\
2.4176 E+04 \\
2.1875 E+04 \\
1.5034 E+04 \\
1.1709 E+04 \\
7.1017 E+03 \\
5.5308 E+03 \\
3.3546 E+03 \\
2.6123 E+03 \\
1.5846 E+03 \\
1.1013 E+02 \\
1.0677 E+01 \\
4.1399 E-01\end{array}$ & $\begin{array}{l}1.8179 E+09 \\
9.3648 E+09 \\
8.7700 E+09 \\
1.7920 E+10 \\
4.3881 E+10 \\
1.8495 E+10 \\
5.0189 E+10 \\
2.6096 E+10 \\
1.2758 E+11 \\
1.9789 E+11 \\
2.0591 E+11 \\
8.2978 E+10 \\
1.6522 E+11 \\
9.7027 E+10 \\
5.0508 E+10 \\
4.9358 E+10 \\
4.5313 E+10 \\
1.0322 E+10 \\
5.0559 E+10 \\
4.2108 E+10 \\
7.7288 E+10 \\
3.5066 E+10 \\
7.9012 E+10 \\
7.0746 E+10 \\
6.9633 E+10 \\
6.3258 E+10 \\
1.1508 E+11 \\
5.0135 E+10 \\
5.8542 E+10 \\
6.0916 E+10 \\
1.0357 E+11 \\
9.3977 E+10 \\
1.0525 E+11 \\
7.5002 E+10 \\
1.1322 E+11 \\
4.2708 E+10 \\
1.2509 E+11 \\
2.7991 E+10 \\
2.6834 E+10 \\
5.0704 E+10 \\
9.2617 E+10 \\
3.0285 E+10 \\
4.5936 E+10 \\
1.2258 E+10 \\
1.6194 E+10 \\
5.9524 E+10 \\
3.8515 E+10 \\
7.5793 E+10 \\
3.7287 E+10 \\
7.5603 E+10 \\
3.7286 E+10 \\
7.2267 E+10 \\
4.3503 E+11 \\
3.5337 E+11 \\
5.4906 E+11 \\
1.1789 E+14\end{array}$ & $\begin{array}{l}1.8179 \mathrm{E}+092 \\
1.1183 \mathrm{E}+102 \\
1.9953 \mathrm{E}+10 \\
3.7873 \mathrm{E}+10 \\
8.1754 \mathrm{E}+10 \\
1.0025 \mathrm{E}+112 \\
1.5044 \mathrm{E}+11 \\
1.7653 \mathrm{E}+112 \\
3.0411 \mathrm{E}+11 \\
5.0201 \mathrm{E}+11 \\
7.0791 \mathrm{E}+11 \\
7.9089 \mathrm{E}+11 \\
9.5611 \mathrm{E}+11 \\
1.0531 \mathrm{E}+12 \\
1.1036 \mathrm{E}+12 \\
1.1530 \mathrm{E}+12 \\
1.1983 \mathrm{E}+12 \\
1.2086 \mathrm{E}+12 \\
1.2592 \mathrm{E}+12 \\
1.3013 \mathrm{E}+12 \\
1.3786 \mathrm{E}+12 \\
1.4137 \mathrm{E}+12 \\
1.4927 \mathrm{E}+12 \\
1.5634 \mathrm{E}+12 \\
1.6330 \mathrm{E}+12 \\
1.6963 \mathrm{E}+12 \\
1.8114 \mathrm{E}+12 \\
1.8615 \mathrm{E}+12 \\
1.92012+12 \\
1.9810 \mathrm{E}+12 \\
2.0845 \mathrm{E}+12 \\
2.1785 \mathrm{E}+12 \\
2.2838 \mathrm{E}+12 \\
2.3588 \mathrm{E}+12 \\
2.4720 \mathrm{E}+12 \\
2.5147 \mathrm{E}+12 \\
2.6398 \mathrm{E}+12 \\
2.6678 \mathrm{E}+12 \\
2.6946 \mathrm{E}+12 \\
2.7453 \mathrm{E}+12 \\
2.8379 \mathrm{E}+12 \\
2.8682 \mathrm{E}+12 \\
2.9142 \mathrm{E}+12 \\
2.9264 \mathrm{E}+12 \\
2.9426 \mathrm{E}+12 \\
3.0021 \mathrm{E}+12 \\
3.0407 \mathrm{E}+12 \\
3.1165 \mathrm{E}+12 \\
3.1537 \mathrm{E}+12 \\
3.2293 \mathrm{E}+12 \\
3.2666 \mathrm{E}+12 \\
3.3389 \mathrm{E}+12 \\
3.7739 \mathrm{E}+12 \\
4.1273 \mathrm{E}+12 \\
4.6764 \mathrm{E}+12 \\
1.2257 \mathrm{E}+14\end{array}$ & $\begin{array}{l}2.9173 E-25 \\
2.6751 E-25 \\
2.5012 E-25 \\
2.3737 E-25 \\
2.2228 E-25 \\
2.1385 E-25 \\
2.0703 E-25 \\
2.0144 E-25 \\
1.9284 E-25 \\
1.7872 E-25 \\
1.6267 E-25 \\
1.4923 E-25 \\
1.3701 E-25 \\
1.2706 E-25 \\
1.2196 E-25 \\
1.3291 E-25 \\
1.1674 E-25 \\
1.0960 E-25 \\
1.0414 E-25 \\
1.0218 E-25 \\
1.0396 E-25 \\
8.5603 E-26 \\
7.9245 E-26 \\
8.7816 E-26 \\
7.3687 E-26 \\
6.8071 E-26 \\
4.9703 E-26 \\
3.3558 E-26 \\
3.8361 E-26 \\
5.6050 E-26 \\
3.5216 E-26 \\
2.9351 E-26 \\
3.9198 E-26 \\
2.0968 E-26 \\
1.8138 E-26 \\
2.4005 E-26 \\
1.4101 E-26 \\
1.0099 E-26 \\
1.4602 E-26 \\
1.3423 E-26 \\
6.4663 E-27 \\
7.1479 E-27 \\
2.3128 E-26 \\
2.0494 E-27 \\
4.3747 E-28 \\
8.1527 E-28 \\
1.0825 E-27 \\
2.2535 E-27 \\
1.3964 E-27 \\
6.3620 E-28 \\
4.3318 E-28 \\
3.1102 E-28 \\
8.2413 E-29 \\
3.1889 E-29 \\
1.3268 E-28 \\
9.8241 E-28\end{array}$ & $\begin{array}{l}5.3034 \mathrm{E}-16 \\
2.5051 \mathrm{E}-15 \\
2.1936 \mathrm{E}-15 \\
4.2536 \mathrm{E}-15 \\
9.7539 \mathrm{E}-15 \\
3.9552 \mathrm{E}-15 \\
1.0391 \mathrm{E}-14 \\
5.2569 \mathrm{E}-15 \\
2.4602 \mathrm{E}-14 \\
3.5367 \mathrm{E}-14 \\
3.3494 \mathrm{E}-14 \\
1.2383 \mathrm{E}-14 \\
2.2636 \mathrm{E}-14 \\
1.2328 \mathrm{E}-14 \\
6.1601 \mathrm{E}-15 \\
6.5603 \mathrm{E}-15 \\
5.2898 \mathrm{E}-15 \\
1.1313 \mathrm{E}-15 \\
5.2654 \mathrm{E}-15 \\
4.3026 \mathrm{E}-15 \\
8.0344 \mathrm{E}-15 \\
3.0018 \mathrm{E}-15 \\
6.2613 \mathrm{E}-15 \\
6.2126 \mathrm{E}-15 \\
5.1310 \mathrm{E}-15 \\
4.3061 \mathrm{E}-15 \\
5.7196 \mathrm{E}-15 \\
1.6824 \mathrm{E}-15 \\
2.2457 \mathrm{E}-15 \\
3.4143 \mathrm{E}-15 \\
3.6474 \mathrm{E}-15 \\
2.7584 \mathrm{E}-15 \\
4.1258 \mathrm{E}-15 \\
1.5726 \mathrm{E}-15 \\
2.0537 \mathrm{E}-15 \\
1.0252 \mathrm{E}-15 \\
1.7638 \mathrm{E}-15 \\
2.8267 \mathrm{E}-16 \\
3.9182 \mathrm{E}-16 \\
6.8061 \mathrm{E}-16 \\
5.9889 \mathrm{E}-16 \\
2.1647 \mathrm{E}-16 \\
1.0624 \mathrm{E}-15 \\
2.5121 \mathrm{E}-17 \\
7.0843 \mathrm{E}-18 \\
4.8529 \mathrm{E}-17 \\
4.1692 \mathrm{E}-17 \\
1.7080 \mathrm{E}-16 \\
5.2066 \mathrm{E}-17 \\
4.8098 \mathrm{E}-17 \\
1.6152 \mathrm{E}-17 \\
2.2477 \mathrm{E}-17 \\
3 \\
1.5852 \mathrm{E}-17 \\
1.1269 \mathrm{E}-17 \\
7.2850 \mathrm{E}-17 \\
1.1582 \mathrm{E}-13\end{array}$ & $\begin{array}{l}5.3034 E-16 \\
3.0355 E-15 \\
5.2291 E-15 \\
9.4827 E-15 \\
1.9237 E-14 \\
2.3192 E-14 \\
3.3582 E-14 \\
3.8839 E-14 \\
6.344 E-14 \\
9.8808 E-14 \\
1.3230 E-13 \\
1.4469 E-13 \\
1.6732 E-13 \\
1.7965 E-13 \\
1.8581 E-13 \\
1.9237 E-13 \\
1.9766 E-13 \\
1.9879 E-13 \\
2.0406 E-13 \\
2.0836 E-13 \\
2.1639 E-13 \\
2.1940 E-13 \\
2.2566 E-13 \\
2.3187 E-13 \\
2.3700 E-13 \\
2.4131 E-13 \\
2.4703 E-13 \\
2.4871 E-13 \\
2.5095 E-13 \\
2.5437 E-13 \\
2.5802 E-13 \\
2.6077 E-13 \\
2.6490 E-13 \\
2.6647 E-13 \\
2.6853 E-13 \\
2.6955 E-13 \\
2.7131 E-13 \\
2.7160 E-13 \\
2.7199 E-13 \\
2.7267 E-13 \\
2.7327 E-13 \\
2.7349 E-13 \\
2.7455 E-13 \\
2.7457 E-13 \\
2.7458 E-13 \\
2.7463 E-13 \\
2.7467 E-13 \\
2.7484 E-13 \\
2.7489 E-13 \\
2.7494 E-13 \\
2.7496 E-13 \\
2.7498 E-13 \\
2.7502 E-13 \\
2.7503 E-13 \\
2.7510 E-13 \\
3.9092 E-13\end{array}$ & $\begin{array}{l}1.3567 E-01 \\
7.7650 E-01 \\
1.3376 E+00 \\
2.4257 E+00 \\
4.9209 E+00 \\
5.9326 E+00 \\
8.5906 E+00 \\
9.9354 E+00 \\
1.6229 E+01 \\
2.5276 E+01 \\
3.3844 E+01 \\
3.7012 E+01 \\
4.2802 E+01 \\
4.5956 E+01 \\
4.7532 E+01 \\
4.9210 E+01 \\
5.0553 E+01 \\
5.0852 E+01 \\
5.2199 E+01 \\
5.3300 E+01 \\
5.5355 E+01 \\
5.6123 E+01 \\
5.7725 E+01 \\
5.9314 E+01 \\
6.0627 E+01 \\
6.1728 E+01 \\
6.3191 E+01 \\
6.3622 E+01 \\
6.4196 E+01 \\
6.5069 E+01 \\
6.6002 E+01 \\
6.6708 E+01 \\
6.7763 E+01 \\
6.8166 E+01 \\
6.8691 E+01 \\
6.8953 E+01 \\
6.9405 E+01 \\
6.9477 E+01 \\
6.9577 E+01 \\
6.9751 E+01 \\
6.9904 E+01 \\
6.9960 E+01 \\
7.0232 E+01 \\
7.0238 E+01 \\
7.0240 E+01 \\
7.0252 E+01 \\
7.0263 E+01 \\
7.0307 E+01 \\
7.0320 E+01 \\
7.0332 E+01 \\
7.0336 E+01 \\
7.0342 E+01 \\
7.0351 E+01 \\
7.0354 E+01 \\
7.0373 E+01 \\
31.0000 E+02\end{array}$ \\
\hline
\end{tabular}


APPENDIX A. Continued.

HFIR KEY 7 LOCATION 8

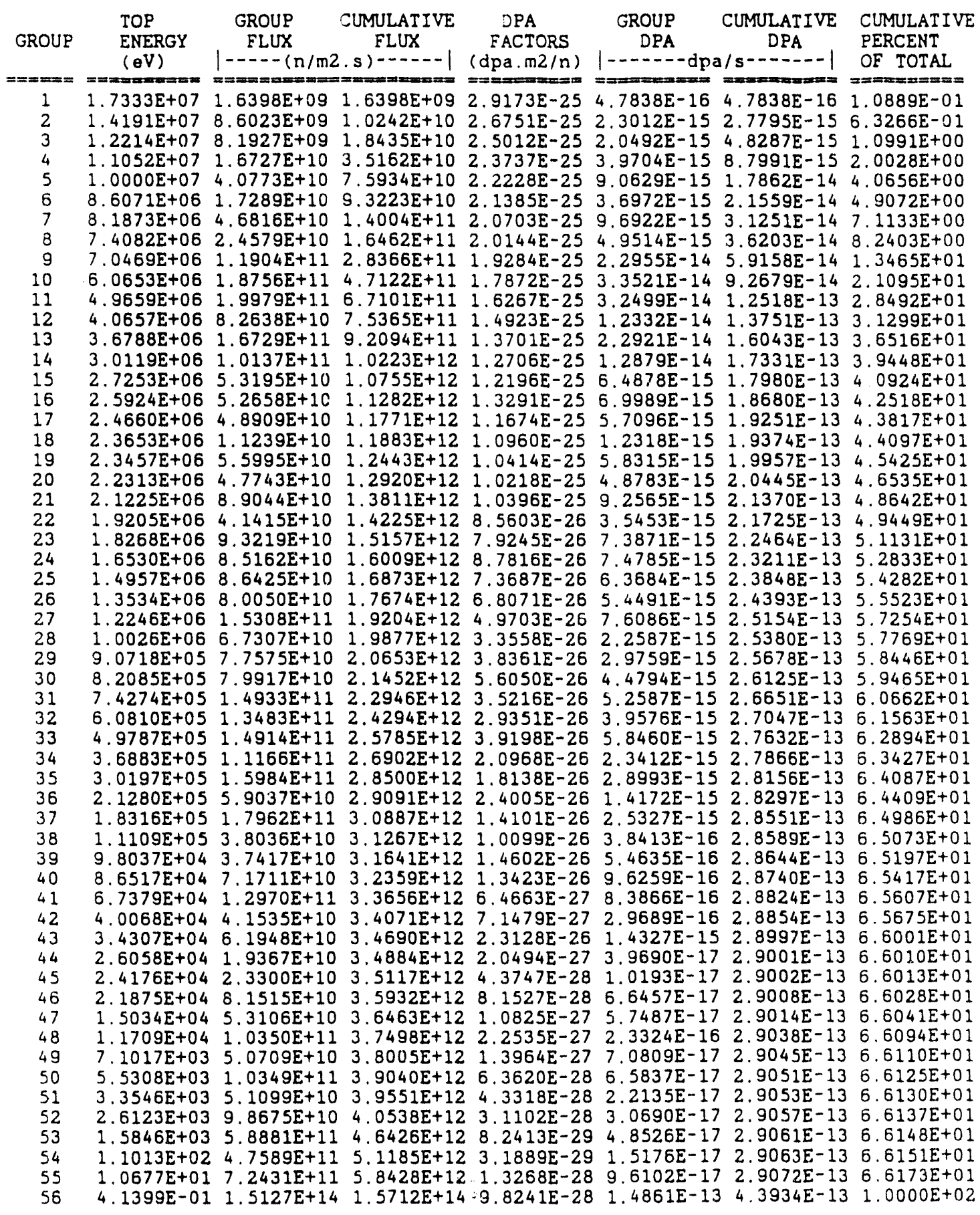


APPENDIX B.

PROCEDURE FOR CALCULATING THE NEUTRON FLUX AT THE HFIR PRESSURE VESSEL

The objective of the calculations was to determine fluxes and responses in the HFIR at Keys 2, 4, 5, and 7 for beginning and end of cycle using biased angular quadrature. The responses were to be the following:
a. ${ }^{58} \mathrm{Ni}(\mathrm{n}, \mathrm{p}){ }^{58} \mathrm{Co}$ reactions,
b. ${ }^{54} \mathrm{Fe}(\mathrm{n}, \mathrm{p}){ }^{54} \mathrm{Mn}$ reactions,
c. Displacement per Atom in $\mathrm{Fe}$,
d. Fluence with energy $>0.1 \mathrm{MeV}$, and
e. Fluence with energy $>1 \mathrm{MeV}$.

Since the three-dimensional transport code would run only on the Cray at K-25, all cross sections and computer codes associated with this work were transferred there.

The first three-dimensional calculation was for key 7 at beginning-ofcycle. This calculation was made with an S10 quadrature for comparison with a calculation made several years earlier to ensure us that the code was working properly. This earlier calculation ${ }^{1}$ to determine the fast $\operatorname{flux}(\mathrm{E}>.1 \mathrm{MeV})$ was made on the Cray under a different operating system. A follow-on calculation yielded the epithermal flux; although a thermal flux was produced from this calculation, it was considered to be in error since the cross sections (from the ELXSIR ${ }^{2}$ library) had been produced to examine non-thermal systems. However, the most recent calculation yielded thermal fluences which were an order of magnitude lower than the follow-on calculated thermal fluences. At this point further work was halted to determine if the latest thermal fluences were indeed correct.

The procedure for calculating the fluences at the various positions in the HFIR were as follows:

1. Cross sections required for the calculations were chosen from the 99 neutron group ANSL-V ${ }^{3}$ These cross sections were located at ORNL on the IBM computer system storage devices. Using the AMPX ${ }^{4}$ modules AJAX and AIM on the IBM system, the appropriate binary cross sections from the ANSL-V AMPX master library were selected and reformatted in card image for the transfer electronically.

2. Using Ethernet and PC/TCP software, the card-image cross sections were transferred to the $\mathrm{K}-25$ Cray system. 
APPENDIX B. Continued.

3. Using the AMPX AIM and AJAX modules, the cross sections were changed from card image to Cray binary and combined into one AMPX master library.

4. One- ${ }^{5}$ and two-dimensional ${ }^{6}$ HFIR geometry models have been previously constructed for the updated HFIR safety analysis. Using the onedimensional model for beginning-of-cycle, the AMPX modules BONAMI and NITAWL were run to self-shield the 99 -group cross sections. Using the AMPX radiation transport module XSDRNPM, the 99 -group cross sections were collapsed to a broader group structure. This broader group structure would reduce the running and data storage requirements for the two- and three-dimensional calculations. The criteria for this broader group cross-section set was that the group fluxes in the water between the permanent beryllium and the pressure vessel could not deviate from the 99 -group fluxes by more than five percent at each space mesh. The final broad-group cross-section set contained 64 neutron groups.

5. DOSDAM $84^{7}$ cross sections for nickel, iron, and iron displacement were collapsed from 640 groups to 64 groups using the one-dimensional 99-group fluxes in a locally written code, CRES.

6. The 64-group cross sections, the two-dimensional HFIR geometry model which included the pressure vessel, and the fission density from the HFIR safety analysis two-dimensional calculation were input to the DORT twodimensional discrete-ordinates radiation transport code ${ }^{8}$. Output from this code included the scalar and directional fluxes throughout the HFIR geometry model.

7. Using the VISTA (VISA) code ${ }^{9}$, the DORT directional fluxes were reformatted for input to the DOTTOR code 10 , which transformed the VISTA twodimensional flux output into a surface boundary source for the threedimensional transport code.

8. The transformed fluxes, together with the three-dimensional model of the beam tube region, were input to the TORT three-dimensional code 11 . Flux output from the calculation was folded by the code with the appropriate cross sections to produce the $\mathrm{Ni}, \mathrm{Fe}$, displacement, and total fluxes $(>.1$ and $1 \mathrm{MeV}$ ) and thermal fluxes. 
APPENDIX B. Continued.

\section{REFERENCES}

1. R.L. Childs, W. A. Rhoades, and L.R. Williams, "Three-Dimensional Calculations of Neutron Streaming in the Beam Tubes of the ORNL HFIR Reactor", Proceedings, 7 th International Conference on Radiation Shielding, VOL II, Sep 1988 .

2. "The ELXSIR Cross-Section Library for LWR Pressure Vessel Irradiation Studies: Part of the LEPRICON Computer Code System", Oak Ridge National Lab, EPRI NP-3654, 1984.

3. W.E. Ford, et al, "ANSL-V: ENDF/B-V Based Multigroup Cross-Section Libraries for Advanced Neutron Source (ANS) Reactor Studies, "Oak Ridge National Lab, ORNL-6618, 1990.

4. N.M. Greene, et al, "AMPX-77: A Modular Code System for Generating Coupled Multigroup Neutron-Gamma Cross-Section Libraries form ENDF/B-IV and/or ENDF/BV", Oak Ridge National Lab, ORNL/CSD/TM-283, to be published.

5. R.T. Primm III, "Reactor Physics Input to the Safety Analysis Report for the High Flux Isotope Reactor", Oak Ridge National Lab, ORNL/TM-11956, October 1991.

6. W.W. Engle, RZ Base Case, Shielding Input to the HFIR SAR, EPM.HFIR.91.001, Jun 1991.

7. W.L. Zijp, et al, "DOSDAM84 - Multigroup Cross Sections in SAND-II Format for Spectral, Integral and Damage Analyses", Radiation Shielding Information Center, Oak Ridge National Lab, DLC-131, 1987.

8. W.A. Rhoades and R.L. Childs, "The DORT Two-Dimensional Discrete Ordinates Transport Code, "Nucl. Sci. \& Engr. 99, 1, 88-89, May 1988.

9. W.A. Rhoades, et al, "Vehicle Code System (VCS) User's Manual", Oak Ridge National Lab, ORNL-TM-4648, Aug 1974.

10. J.L. Thompson, et al, "Development and Evaluation of DOTTOR, a Computer Code to Couple Two-Dimensional to Three-Dimensional Discrete Ordinates Calculations", Oak Ridge National Lab, ORNL/TM-9919, 1986.

11. W.A. Rhoades and R.L. Childs, "The TORT Three-Dimensional Discrete Ordinates Neutron/Photon Transport Code", Oak Ridge National Lab, ORNL-6268, Nov 1987. 
APPENDIX C. GROUP FLUXES FOR ALL POSITIONS IN KEY 7.

Key 7 Group Fluxes ( $\mathrm{m}^{-2} \mathrm{~s}^{-1}$ )

\begin{tabular}{|c|c|c|c|c|c|c|}
\hline $\mathrm{p}$ & lower & upper & Position 1 & Position 2 & Positton 3 & Position 4 \\
\hline $\begin{array}{r}1 \\
2 \\
3 \\
4 \\
5 \\
6 \\
7 \\
8 \\
9 \\
10 \\
11 \\
12 \\
13 \\
14 \\
15 \\
16 \\
17 \\
18 \\
19 \\
20 \\
21 \\
22 \\
23 \\
24 \\
25 \\
26 \\
27 \\
28 \\
29 \\
30 \\
31 \\
32 \\
33 \\
34 \\
35 \\
36 \\
37 \\
38 \\
39 \\
40 \\
41 \\
42 \\
43 \\
44 \\
45 \\
46 \\
47 \\
48 \\
49\end{array}$ & 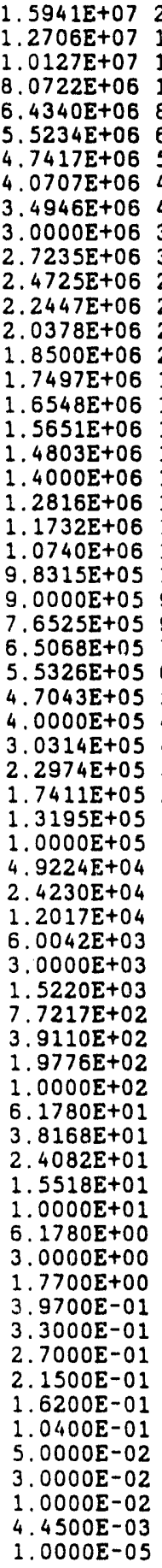 & 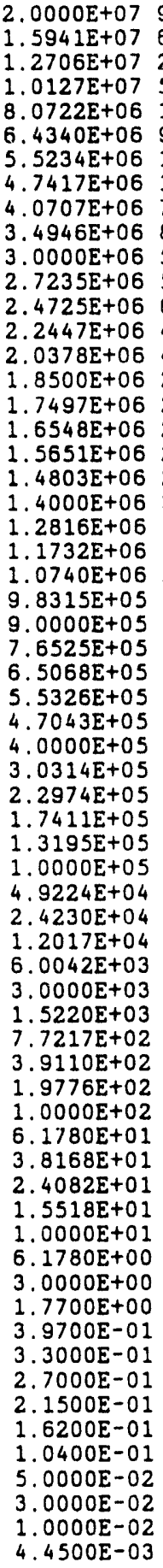 & 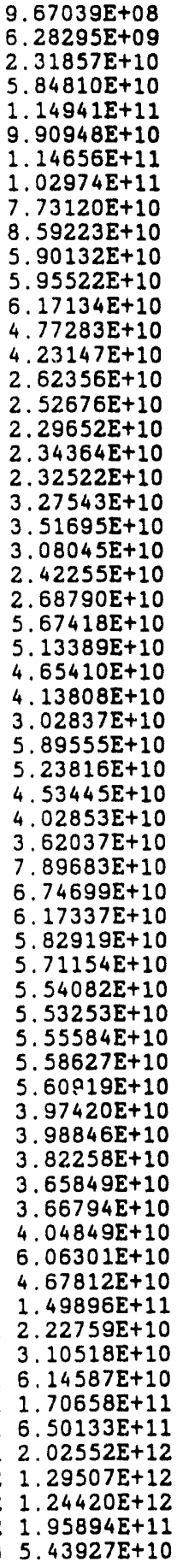 & $\begin{array}{l}9.77613 E+08 \\
6.37299 E+09 \\
2.35544 E+10 \\
5.95098 E+10 \\
1.17719 E+11 \\
1.02123 E+11 \\
1.18764 E+11 \\
1.07008 E+11 \\
8.05236 E+10 \\
8.95950 E+10 \\
6.15367 E+10 \\
6.21735 E+10 \\
6.44766 E+10 \\
4.98565 E+10 \\
4.42197 E+10 \\
2.74248 E+10 \\
2.64132 E+10 \\
2.40084 E+10 \\
2.45046 E+10 \\
2.43144 E+10 \\
3.42453 E+10 \\
3.67791 E+10 \\
3.22102 E+10 \\
2.53238 E+10 \\
2.810011 E+10 \\
5.93332 E+10 \\
5.36900 E+10 \\
4.86763 E+10 \\
4.32874 E+10 \\
3.16716 E+10 \\
6.16613 E+10 \\
5.47903 E+10 \\
4.74340 E+10 \\
4.21423 E+10 \\
3.78746 E+10 \\
8.26180 E+10 \\
7.05931 E+10 \\
6.45958 E+10 \\
6.09985 E+10 \\
5.97707 E+10 \\
5.79875 E+10 \\
5.790410+10 \\
5.81514 E+10 \\
5.84733 E+10 \\
5.87166 E+10 \\
4.16037 E+10 \\
4.17548 E+10 \\
4.00199 E+10 \\
3.83036 E+10 \\
3.840410 E+10 \\
4.23904 E+10 \\
6.34874 E+10 \\
4.89892 E+10 \\
1.569910+11 \\
2.33313 E+10 \\
3.25239 E+10 \\
6.43744 E+10 \\
1.78758 E+11 \\
6.81005 E+11 \\
2.12173 E+12 \\
1.35659 E+12 \\
1.30332 E+12 \\
2.05202 E+11 \\
5.69772 E+10\end{array}$ & 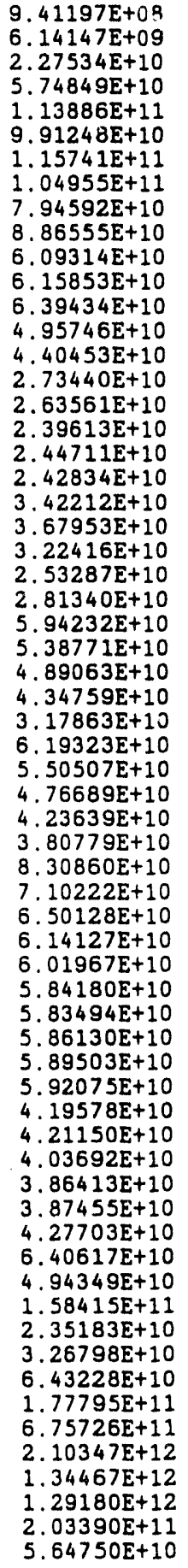 & $\begin{array}{l}8.79031 E+08 \\
5.71281 E+09 \\
2.09386 E+10 \\
5.24198 E+10 \\
1.04386 E+11 \\
9.17451 E+10 \\
1.07986 E+11 \\
9.90374 E+10 \\
7.59241 E+10 \\
8.51396 E+10 \\
5.88829 E+10 \\
5.99380 E+10 \\
6.29022 E+10 \\
4.95879 E+10 \\
4.42915 E+10 \\
2.75791 E+10 \\
2.68165 E+10 \\
2.44140 E+10 \\
2.49682 E+10 \\
2.47013 E+10 \\
3.54440 E+10 \\
3.81146 E+10 \\
3.39715 E+10 \\
2.67813 E+10 \\
2.98756 E+10 \\
6.20070 E+10 \\
5.77817 E+10 \\
5.31602 E+10 \\
4.59887 E+10 \\
3.39908 E+10 \\
6.61908 E+10 \\
5.83638 E+10 \\
4.99652 E+10 \\
4.47044 E+10 \\
3.97660 E+10 \\
8.63648 E+10 \\
7.36516 E+10 \\
6.69056 E+10 \\
6.27699 E+10 \\
5.16637 E+10 \\
5.95792 E+10 \\
5.93540 E+10 \\
5.94935 E+10 \\
5.96669 E+10 \\
5.989010+10 \\
4.23748 E+10 \\
4.24778 E+10 \\
4.06617 E+10 \\
3.88673 E+10 \\
3.89115 E+10 \\
4.28805 E+10 \\
6.40643 E+10 \\
4.924410+10 \\
1.54703 E+11 \\
2.30621 E+10 \\
3.08752 E+10 \\
5.74799 E+10 \\
1.51381 E+11 \\
5.59390 E+11 \\
1.72051 E+12 \\
1.09439 E+12 \\
1.04813 E+12 \\
1.64784 E+11 \\
4.57406 E+10\end{array}$ \\
\hline & & & & & & $7.78362 \mathrm{E}+12$ \\
\hline
\end{tabular}


APPENDIX C. Continued.

Key 7 Group Fluxes (n m $\mathrm{m}^{-2} \mathrm{~s}^{-1}$ )

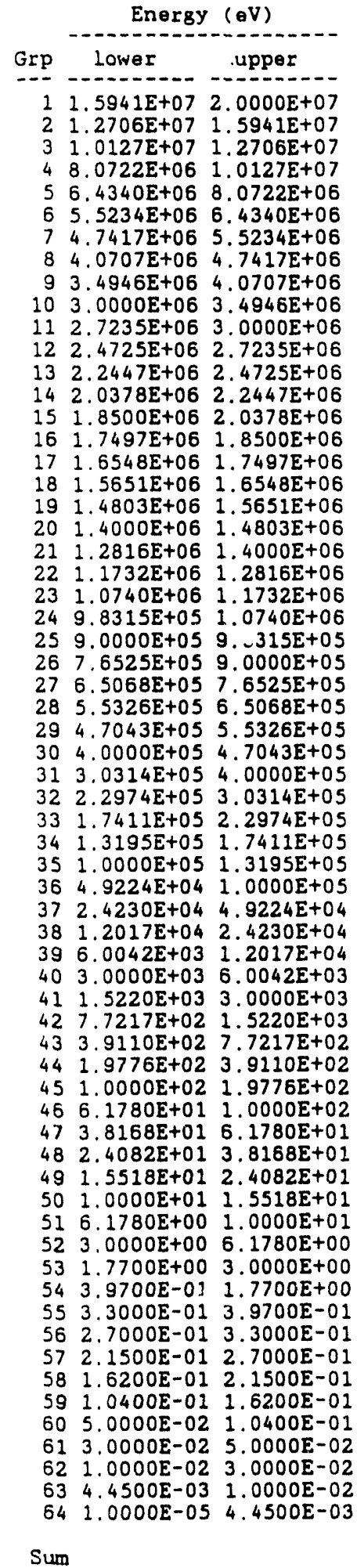

\begin{tabular}{|c|c|c|c|}
\hline & & sition & $\mathrm{n}$ \\
\hline 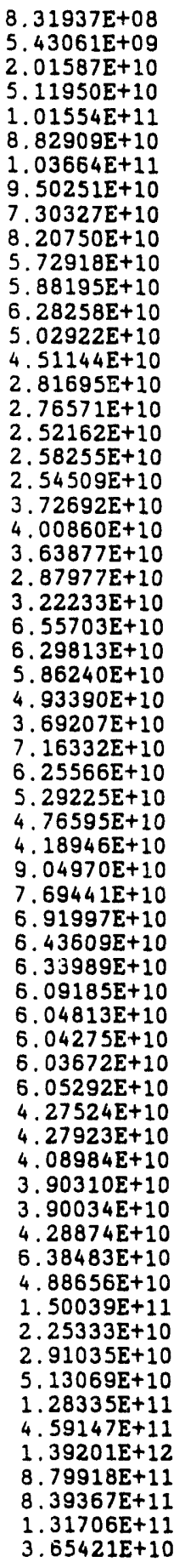 & $\begin{array}{l}8.16760 E+08 \\
5.35025 E+09 \\
1.99376 E+10 \\
5.09133 E+10 \\
1.01769 E+11 \\
8.96236 E+10 \\
1.06551 E+11 \\
9.86275 E+10 \\
7.57210 E+10 \\
8.51816 E+10 \\
5.92236 E+10 \\
6.06566 E+10 \\
6.45210 E+10 \\
5.09430 E+10 \\
4.54758 E+10 \\
2.83800 E+10 \\
2.76716 E+10 \\
2.52068 E+10 \\
2.58166 E+10 \\
2.55227 E+10 \\
3.67865 E+10 \\
3.96341 E+10 \\
3.54611 E+10 \\
2.79259 E+10 \\
3.11992 E+10 \\
6.45878 E+10 \\
6.06991 E+10 \\
5.60739 E+10 \\
4.83458 E+10 \\
3.57286 E+10 \\
6.95813 E+10 \\
6.13417 E+10 \\
5.24999 E+10 \\
4.70042 E+10 \\
4.17838 E+10 \\
9.07539 E+10 \\
7.74082 E+10 \\
7.02448 E+10 \\
6.59150 E+10 \\
6.47649 E+10 \\
6.25651 E+10 \\
6.23190 E+10 \\
6.24551 E+10 \\
6.26258 E+10 \\
6.28543 E+10 \\
4.44685 E+10 \\
4.45732 E+10 \\
4.26636 E+10 \\
4.07770 E+10 \\
4.08184 E+10 \\
4.49739 E+10 \\
5.71704 E+10 \\
5.16119 E+10 \\
1.61645 E+11 \\
2.41000 E+10 \\
3.20509 E+10 \\
5.90843 E+10 \\
1.54229 E+11 \\
5.67020 E+11\end{array}$ & $\begin{array}{l}7.86999 E+08 \\
5.12697 E+09 \\
1.91980 E+10 \\
4.96084 E+10 \\
9.96386 E+10 \\
8.81380 E+10 \\
1.05425 E+11 \\
9.95038 E+10 \\
7.79566 E+10 \\
8.90046 E+10 \\
6.255410+10 \\
6.48177 E+10 \\
7.02631 E+10 \\
5.662510+10 \\
5.10451 E+10 \\
3.20845 E+10 \\
3.16129 E+10 \\
2.88493 E+10 \\
2.96748 E+10 \\
2.92783 E+10 \\
4.29140 E+10 \\
4.64464 E+10 \\
4.22345 E+10 \\
3.32958 E+10 \\
3.75182 E+10 \\
7.67679 E+10 \\
7.46477 E+10 \\
7.09855 E+10 \\
5.94812 E+10 \\
4.42309 E+10 \\
8.68538 E+10 \\
7.64575 E+10 \\
6.45463 E+10 \\
5.8584 E E+10 \\
5.15646 E+10 \\
1.11523 E+11 \\
9.52103 E+10 \\
8.64525 E+10 \\
8.036711 E+10 \\
7.93805 E+10 \\
7.64454 E+10 \\
7.60697 E+10 \\
7.61731 E+10 \\
7.62606 E+10 \\
7.66058 E+10 \\
5.41871 E+10 \\
5.43054 E+10 \\
5.19646 E+10 \\
4.96485 E+10 \\
4.96695 E+10 \\
5.46838 E+10 \\
8.15609 E+10 \\
5.25238 E+10 \\
1.92835 E+11 \\
2.91130 E+10 \\
3.79923 E+10 \\
6.84981 E+10 \\
1.74996 E+11 \\
6.33518 E+11 \\
1.92893 E+12 \\
1.22048 E+12 \\
1.16446 E+112 \\
1.82712 E+11 \\
5.06855 E+10\end{array}$ & 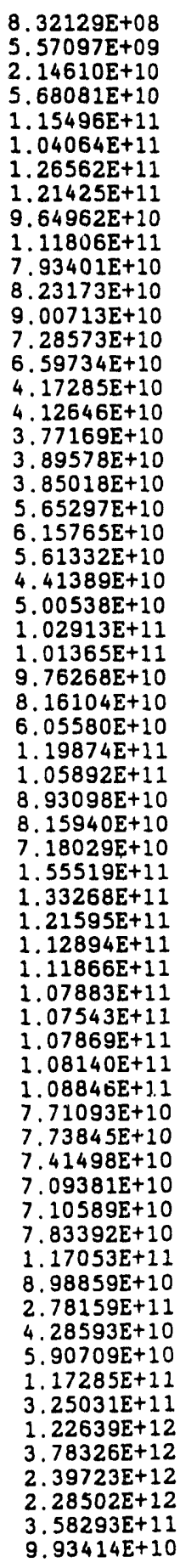 \\
\hline & $7.93389 \mathrm{E}+12$ & $8.93497 \mathrm{E}+12$ & $1.53335 E+13$ \\
\hline
\end{tabular}




\section{APPENDIX D. SOURCES AND CHEMICAL ANALYSES OF MATERIALS USED IN DOS 1 DOSIMETRY EXPERIMENT}

Nickel Wire: $\quad$ Materials Research Corporation, Orangeburg, New York 10962 Lot No. 28/006344-020481.

Elements detected (wppm):

$\begin{array}{rrrrrrrr}\mathrm{C} & 15.0 ; & \mathrm{Ag} & <0.1 ; & \mathrm{Al} & 0.9 ; & \mathrm{Ca} & 0.45 \\ \mathrm{~N} & <5.0 ; & \mathrm{Cr} & 2.0 ; & \mathrm{Cu} & <0.1 ; & \mathrm{Fe} & 20.0 \\ \mathrm{Cl} & 1.0 ; & \mathrm{Ga} & <0.1 ; & \mathrm{K} & 0.2 ; & \mathrm{Mg} & 2.0 \\ \mathrm{O} & 12.0 ; & \mathrm{Mo} & 0.25 ; & \mathrm{Na} & 0.15 ; & \mathrm{Nb} & <0.1 \\ \mathrm{H} & <1.0 ; & \mathrm{Pb} & <0.1 ; & \mathrm{Sb} & 0.5 ; & \mathrm{Si} & 17.0 \\ \mathrm{~S} & 0.25 ; & \mathrm{Sn} & 1.2 ; & \mathrm{Ta} & <0.2 ; & \mathrm{Ti} & <0.1 \\ \mathrm{Ni} & \text { balance; } & \mathrm{W} & <0.1 ; & \mathrm{Zn} & <0.1 ; & \mathrm{Zr} & 0.65\end{array}$

Gold Wire: $\quad J o h n s o n$ Matthey Chemicals Limited, Royston, Hertfordshire, SG85HE, England.

Batch No. 1521

Elements Detected (wppm): Ca 10; $\mathrm{Ag} \quad 4: \mathrm{Cu} \quad 2: \mathrm{Si} \quad 1 ; \mathrm{Mg} \quad$ 1: Au balance

Silver Wire: Johnson Matthey Chemicals Limited, Royston, Hertfordshire, SG85HE, England.

Batch No. W11073

Elements detected (wppm): $\mathrm{Cu}$ 7; $\mathrm{Fe} \quad 1 ; \mathrm{Mg}<1 ; \mathrm{Ag}$ balance

Cobalt Wire: $\quad$ ORNL Dosimeter Inventory.

Analyzed by neutron activation analysis at ORNL.

Elements detected: Co only

Neptunium Oxide Wire: $\quad$ ORNL Dosimeter Inventory.

Batch No. ORNL Np 83-1, dosimeter No. 10

Coulometric analysis: $0.8834 \mathrm{mg} \mathrm{Np}$ per g material

Isotopic analysis: $99.999 \mathrm{wt} \% \mathrm{~Np}-237$. Wt of Np-237: $8.253 \mathrm{mg}$.

Material is encapsulated in vanadium; total wt is $54.16 \mathrm{mg}$.

Aluminum-Lithium Wire: Rockwell International Corp. via Central Bureau for Nuclear

Measurements, Geel, Belgium.

Batch No. SP 3335, Rockwell Lot 5.

Elements detected (wppm):

In base aluminum:

$\mathrm{B}, \mathrm{Li}<1 ; \mathrm{Ag}, \mathrm{Zn}, \mathrm{Si}, \mathrm{Mn}, \mathrm{Fe}<25 ; \mathrm{Cu}, \mathrm{Mg}, \mathrm{Pb}, \mathrm{Ni}<40$

Isotopic analysis of $\mathrm{Li}: 95.82 \pm 0.08$ at. $\% \mathrm{Li}-6,4.18 \pm .08 \mathrm{Li}-7$

Total Li content of alloy: $0.705 \pm 0.025 \mathrm{wt} \%$ 
APPENDIX D. Continued.

Aluminum-Boron Wire:

Rockwell International Corp. via Central Bureau for Nuclear Measurements, Geel, Belgium

Batch No. SP 3336

Elements detected (wppm):

In base aluminum:

$\mathrm{Mg}$ 7; $\mathrm{Ca}, \mathrm{Na}, \mathrm{B} \leq 4 ; \mathrm{Ag} \quad 0.5 ; \mathrm{Cd}, \mathrm{Cu} \leq 1 ; \mathrm{Cr}, \mathrm{Fe} \quad 3 ; \mathrm{Si}$ 5; Ti $\leq 4$ Isotopic analysis of $\mathrm{B}$ : Natural isotopic composition

Total B content of alloy: $0.50 \mathrm{wt} \%$

Beryllium Chips: $\quad$ Rockwell International Co., Canoga Park, CA 91304

Batch No. K646B, Lot 7

Elements detected (wppm):

Fe 19; Si 20; $\mathrm{Mn}$ 56; $\mathrm{Mg}$ 3.5; $\mathrm{Cr}$ 8.4; Be balance

Gadolinium Vial: ORNL Dosimeter Inventory.

Elements detected (wppm):

Al 9.5; Mn 0.19; W 21; Co 4.4; Hf 143; U 9.5; Gd balance

Aluminum Vial: $\quad$ ORNL Dosimeter Inventory.

Elements detected (wt \%):

$\mathrm{Mg}$ 1.0; Si 0.56; Cr 0.18; Cu 0.26; Fe 0.25; Mn 0.04, Ti 0.01, Zn 0.12;

Al balance

Aluminum Foil: $\quad$ ORNL Dosimeter Inventory.

Elements detected (wppm):

Mg 100; $\mathrm{Si} 100 ; \mathrm{Cr}<10 ; \mathrm{Cu}$ 10; Fe 600; Mn 50; Ti 50; $\mathrm{Zn} \mathrm{20;} \mathrm{Al} \mathrm{balance}$

Ferritic Steel

Dosimeter Block: Machine Shop

Elements detected (wt \%):

Mn 2.0; $\mathrm{Ni}$ 0.2; $\mathrm{Si} \leq 0.05 ; \mathrm{Cr}$ 0.2; $\mathrm{S}$ 0.1; P 0.005; Mo 0.02;

Co $0.005 ; \mathrm{Cu} \quad 0.5 ; \mathrm{Mg}$ 0.001; As $0.1 ; \mathrm{Sb} \quad 0.005 ; \mathrm{Zn} 0.01 ; \mathrm{Fe}$ balance

Stainless Steel Container: ORNL Research Reactor Division.

The dosimeter container is a standard 304L stainless steel can \# 87-13 obtained from the inventory of the HFIR surveillance program. 


\section{APPENDIX E. STANDARD SOLUTION OF RADIONUCLIDES USED TO CALIBRATE GAMMA SPECTROSCOPES.}

Ameraham International ple

Amersham Laboratories
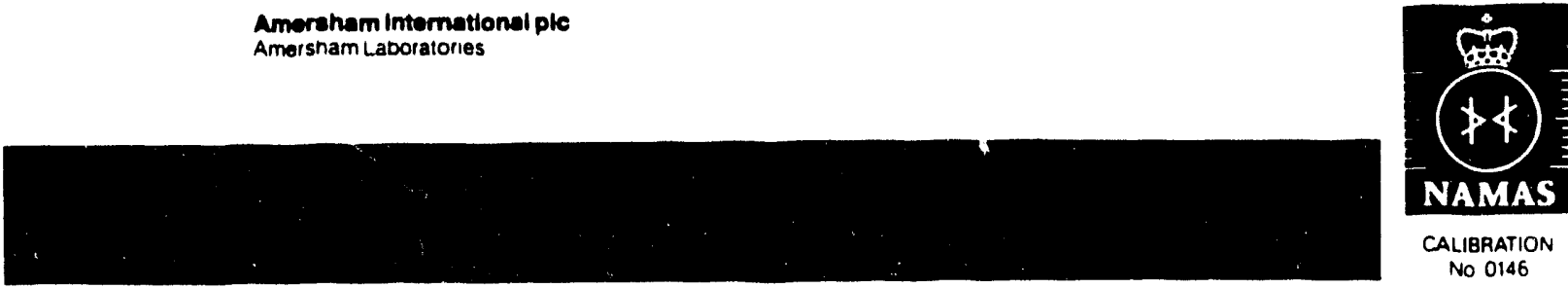

NAMAS

CALIBRATION

Producx code: $\quad$ QCY. 48

Solution number:

$\mathrm{R} 2 / 15 / 46$

This mixed radionuclide gamma-ray reference standard consists of a solution in $4 \mathrm{M} \mathrm{HCl}$ of the ten radionuclides listed below.

Messurement and Accuracy

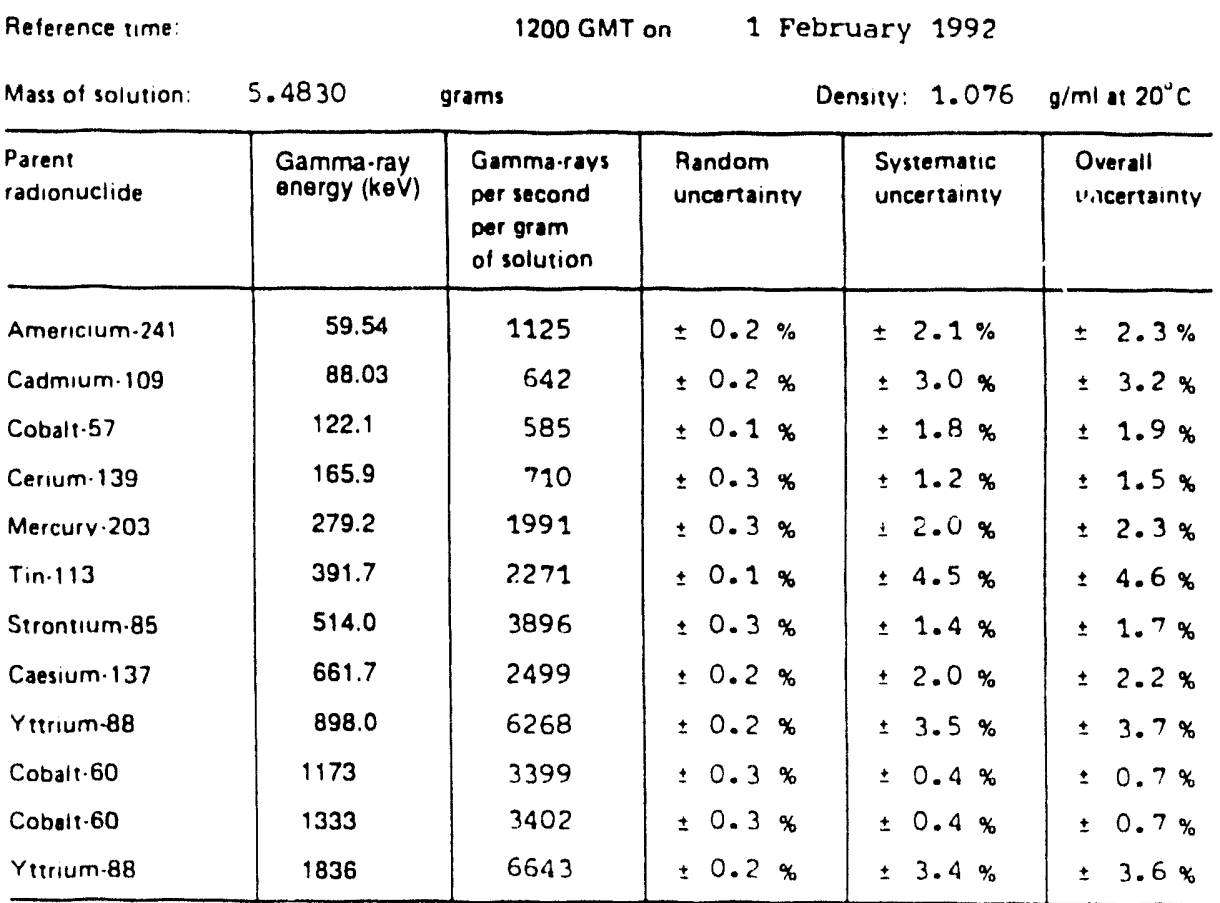

Purity

At the reference ime the solution also contained the following impurities

Cadmium-115m less than 2.6 becquerels (0.070 nanocurles) per aram.

Chlorine-36 equal to 16.4 becquerels (0.44 nanocuries) per gram.

Cobalt-56 less than 0.24 becquerels $(0.0065$ nanocuries) fer gram.

Indium-114m equal to 6.0 becquerels $(0.16$ nanocuries) per aram.

Romarks Further details, including composition of the solutiof, methods \& I measurement, decay scheme assumptions decay tables and definitions of uncertainties, are given in the data sheet accompanying this certificate.

This product meets the quality assurance requiremenis of NAC Regulatory Guide 4.15 for achieving explicit NIST traceability as defined in NCRP58 (1985).

Approved

Signatory

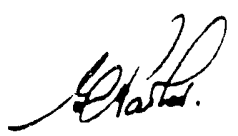

G D M Parker

Page 1 of 


\section{INTERNAL DISTRIBUTION}

1-2. Central Research Library

3. Document Reference Section

4-5. Laboratory Records Department

6. Laboratory Records Department, RC

7. ORNL Patent Section

8-10. M\&C Records Office

11-15. C. A. Baldwin

16. E. C. Beahm

17. P. F. Becher

18. J. A. Chapman

19. R. D. Cheverton

20-21. W. R. Corwin

22-23. F. F. Dyer

24. K. F. Eckerman

25-29. K. Farrell

30. G. F. Flanagan

31. O. F. Fman

32. M. L. Grossbeck

33-34. F. M. Haggag

35. R. W. Hobbs

36-40. F. B. Kam

41. H. T. Kerr

42. J. F. King
43. E. H. Krieg, Jr.

44. L. K. Mansur

45. D. W. McDonald

46. J. G. Merkle

47. R. K. Nanstad

48-49. J. V. Pace, III

50. J. E. Pawel

51-52. L. Robinson

53. D. L. Selby

54. C. S. Sims

55. R. D. Spence

56. F. W. Stallman

57. R. E. Stoller

58. R. M. Westfall

59. S. K. Whatley

60. S. J. Zinkle

61. Y. Austin Chang (Consultant)

62. H. W. Foglesong (Consultant)

63. J. J. Hren (Consultant)

64. E. L. Menger (Consultant)

65. J. G. Simon (Consultant)

66. K. E. Spear (Consultant)

\section{EXTERNAL DISTRIBUTION}

67. BATTELLE NORTHWEST LABORATORIES, Richland, Washington, 99352

L. R. Greenwood

68-71 BROOKHAVEN NATIONAL LABORATORY, Materials Department, 76 Cornell, Upton, NY 11973
N. Holden
J. O'Conner
D. Rorer
P. R. Tichler

72 EG\&G IDAHO, INC.. P.O. Box 1625, Idaho Falls, ID 83415

J. W. Rogers 
73 HANFORD ENGINEERING DEVELOPMENT LABORATORY, P.O. Box 1970 , Richland, WA 99352
M. L. Hamilton

74. JAPAN ATOMIC ENERGY RESEARCH INSTITUTE, Department of Fuels and Materials Research, Tokai-mura, Ibaraki-ken, 319-11 Japan

75. MATERIALS ENGINEERING ASSOCIATES, 9700B Martin Luther King, Jr., Highway, Lanham, MD 20706

76. NATIONAL INSTITUTE OF STANDARDS AND TECHNOLOGY, Gaithersburg, MD 20899

D. E. McGary

77-81. NRC, RES/Division of Engineering, Washington, DC 20555
A. Hiser (MS NS 217C)
S. N. Malik (MS NS 217C)
M. E. Mayfield (MS NS 217C)
C. Z. Serpan (MS NS 217C)
A. Taboada (MS NS 217C)

82. ROCKWEll INTERNATIONAL CORPORATION, Canoga Park, CA, 91303

B. M. Oliver

83-84. UNIVERSITY OF CALIFORNIA, Department of Chemical and Nuclear Engineering, Ward Memorial Drive, Santa Barbara, CA 93106

G. E. Lucas

G. R. Odette

85. WESTINGHOUSE SAVANNAH RIVER COMPANY, Savannah River Laboratory, Aiken, SC 29808

M. R. Louthan, Jr.

86. DOE, Division of Magnetic Fusion Energy, Washington, DC 20545

F. W. Wiffen (ER-533, J224/GTN)

87-89. DOE, Division of Materials Sciences, Washington, DC 20545

J. B. Darby (ER-131, J321/GTN)

R. J. Gottschall (ER-131, J321/GTN)

I. L. Thomas (ER-132, J321/GTN) 
90. DOE, Office of Fossil Energy, Washington. DC 20545

M. I. Singer (FE-14, B115/GTN)

91. DOE, OAK RIDGE OPERATIONS OFFICE, P.O. Box 2001, Oak Ridge, TN 37831-8600

Office of Assistant Manager for Energy Research and Development

92-93 DOE, OFFICE OF SCIENTIFIC AND TECHNICAL INFORMATION, P.O. Box 62 , Oak Ridge, TN 37831

For distribution as shown in DOE/OSTI-4500, Distribution Category UC-404 (Materials) 

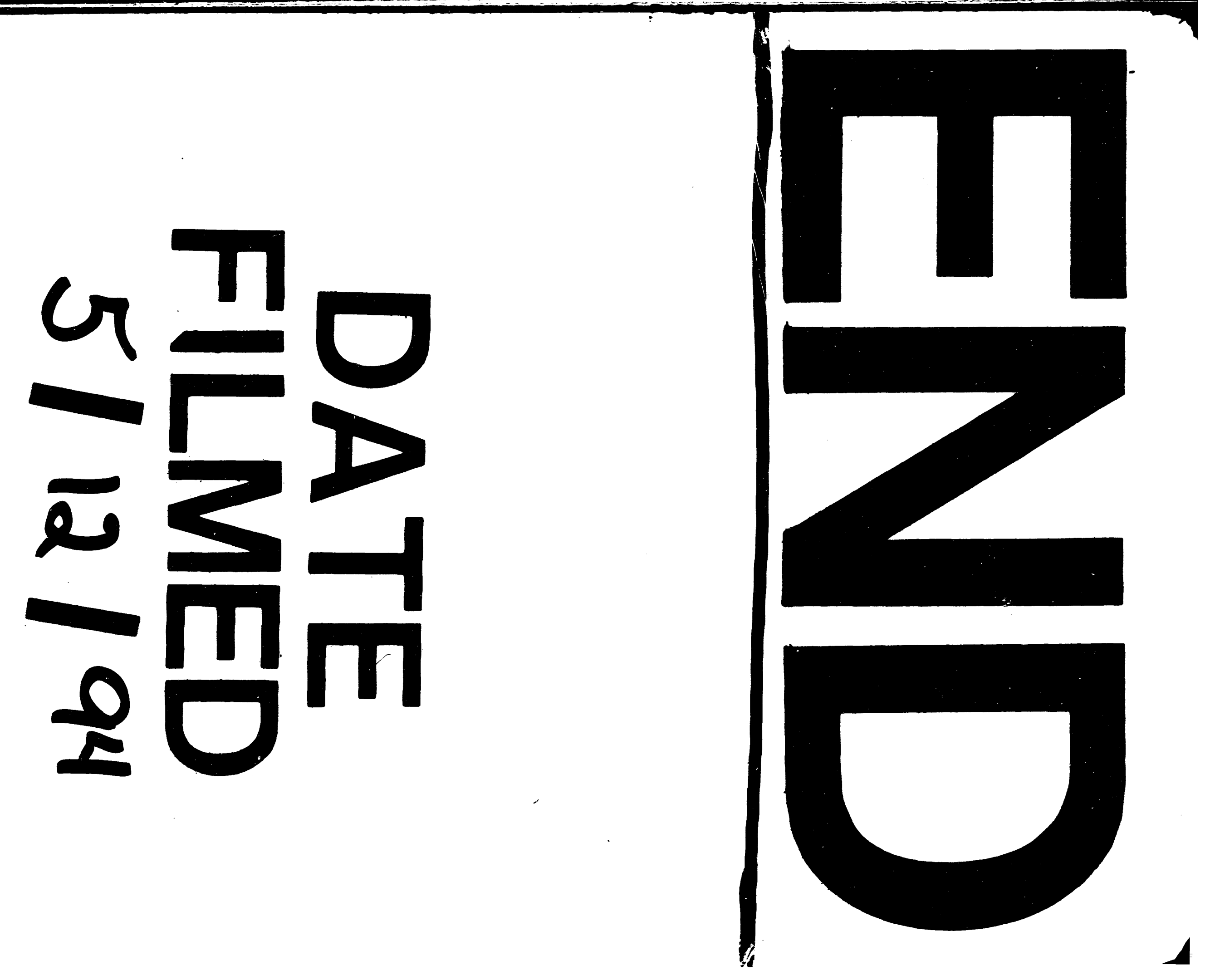
